Estudios Constitucionales, Año 16, No 1, 2018 pp. 327-364

ISSN 07180195

Centro de Estudios Constitucionales de Chile Universidad de Talca

"La pobreza y su tratamiento en la jurisprudencia de la

Corte Constitucional de Colombia (1991-2015)"

María Angélica Nieto Rodríguez - Carlos Mauricio López Cárdenas

\title{
LA POBREZA Y SU TRATAMIENTO EN LA JURISPRUDENCIA DE LA CORTE CONSTITUCIONAL DE COLOMBIA (1991-2015)* \author{
Colombian Constitutional Court (1991-2015)
} \\ POVERTY AND ITS TREATMENT IN THE JURISPRUDENCE OF THE
}

\author{
María Angélica Nieto Rodríguez ${ }^{* *}$ \\ Universidad del Rosario - Colombia \\ mariaan.nieto@urosario.edu.co / nietorod.maria@hotmail.com \\ Carlos Mauricio López Cárdenas ${ }^{* * *}$ \\ Universidad del Rosario - Colombia \\ carlosm.lopez@urosario.edu.co / carloslop12@hotmail.com
}

RESUMEN: El presente trabajo busca realizar un análisis cualitativo y cuantitativo del fenómeno social y económico de la pobreza por parte de la jurisprudencia de la Corte Constitucional de Colombia, con el fin de observar (i) el grado de protección que se ha prohijado a personas que por su precaria condición socio económica se encuentran en una situación de especial vulnerabilidad, (ii) el contenido $y$ alcance de los derechos tutelados, (iii) las órdenes proferidas y (iv) las consecuencias constitucionales que ello implica en materia de judicialización de la politica para combatir la pobreza.

PALABRAS CLAVE: Pobreza, políticas públicas, jurisprudencia constitucional, derechos económicos sociales y culturales, derechos fundamentales, constitucionalismo de la pobreza.

ABSTRACT: The present work aims to realize a quantitative and qualitative analysis of the social and legal phenomenon of poverty by the jurisprudence of the Colombian Constitutional Court with the finality of observe (i) the protection level recognized to people whose precarious social economic condition puts them in a special vulnerability situation, (ii) the aim and scope of the protected rights,

\footnotetext{
* Artículo recibido el 23 de abril de 2016 y aprobado el 11 de abril de 2018.

** Especialista en Derecho Sustantivo y Contencioso Constitucional de la Pontificia Universidad Javeriana - Colombia y abogada de la Universidad del Rosario - Colombia. Actualmente, se desempeña como Coordinadora del Área de Pro Bono del prestigioso estudio jurídico Gómez-Pinzón Zuleta en Colombia. Orcid ID: 0000-0002-9385-1917.

*** Doctor en Derecho y Magíster en Derecho Internacional de la Universidad Complutense de Madrid España, Magíster en Derecho Administrativo y abogado de la Universidad del Rosario - Colombia. Actualmente, se desempeña como profesor principal de carrera académica e investigador del Grupo de Derecho Público de la Facultad de Jurisprudencia de la Universidad del Rosario. Orcid ID: 0000-0003-4316-5238.
} 
(iii) the orders that had been proffered and (iv) the constitutional consequences that it implies in matter of judicialization of policies to fight against poverty.

KEYWORDS: Poverty, public politics, constitutional jurisprudence, social economic and cultural rights, fundamental rights, poverty constitutionalism.

\section{INTRODUCCIÓN}

La pobreza, como eje del presente estudio, es un fenómeno complejo de orden social y económico que por definición comporta la escasez de bienes y servicios básicos que degenera en "la insatisfacción de las necesidades básicas como alimento, vivienda, educación, salud, o como algunos han identificado, carencia de una vida digna". ${ }^{1}$, lo cual, en su conjunto afecta negativamente el desarrollo del individuo y el cumplimiento de los cometidos estatales relacionados con el bienestar personal, especialmente, en lo que toca con la garantía de unas condiciones básicas que permitan alcanzar un nivel mínimo de vida.

En ese sentido, la Organización de las Naciones Unidas ha señalado que la pobreza es un fenómeno que abarca una multipolaridad de elementos que esencialmente afectan la dignidad humana desde la perspectiva del desarrollo personal y social del individuo:

"la pobreza es fundamentalmente una denegación de opciones y oportunidades, una violación de la dignidad humana. Es la falta de capacidad elemental para participar efectivamente en la sociedad. Es no tener lo suficiente para alimentar y vestir a una familia, no tener acceso a escuelas, dispensarios, no disponer de tierra para producir alimento o empleo para ganarse la vida, no tener acceso al crédito. Es la inseguridad, la impotencia y la exclusión de las personas, los hogares y las comunidades. Es la susceptibilidad a la violencia, y a menudo significa vivir en ambientes marginales y frágiles, sin acceso a agua apta para el consumo ni al saneamiento"2.

La pobreza se consolida - en consecuencia- como un factor determinante en las dinámicas de exclusión social ${ }^{3}$, toda vez que disminuye los niveles de participación ciudadana de aquellos sectores sociales con condiciones de vida precarias,

1 Aguirre (2009), p. 25. En sentido similar Lo Vuolo et al. (2004), pp. 28-33. Un análisis sobre las teorías contemporáneas del concepto de pobreza en STARK (2009).

2 NACIONeS Unidas (1998), párr. 3.

3 "La pobreza, en todas las variantes que se postule, no es el único problema social sino una de las formas en que se expresan los problemas sociales. La pobreza suele presentarse conjuntamente $-\mathrm{y}$ muchas veces confundirse-con otras formas de privación de elementos esenciales para que las personas puedan desarrollarse de forma "normal" en la sociedad". Abramovich y Pautassi (2006), p. 10. 
que se ven obligados a apartarse de la colectividad, cuyas estructuras sociales e institucionales hacen que el nivel de representatividad de sus intereses y necesidades se vea reducido sustancialmente ${ }^{4}$.

Dentro de este contexto de exclusión, a las autoridades estatales se les impone un deber positivo de erradicar en la mayor medida de lo posible las desigualdades sociales existentes, poniendo especial cuidado y diligencia en la satisfacción de las necesidades de quienes se encuentran en condiciones de pobreza y desposeimiento, adoptando dinámicas incluyentes que generen esquemas proactivos de superación de pobreza, reemplazando así las tradicionales dinámicas asistencialistas en materia de política pública. En tal sentido, uno de los principales retos que se deben superar sobre este punto radica en consolidar y fortalecer la

“capacidad de guiar con estándares y principios la actuación de los Estados democráticos en las situaciones concretas, tanto la jurisprudencia de los tribunales, a fin de determinar el alcance de los derechos, como los procesos de formulación de políticas públicas, contribuyendo de ese modo al fortalecimiento de las garantías institucionales y sociales de esos derechos en los diferentes espacios nacionales". ${ }^{5}$

Partiendo de lo anterior, el presente estudio se estructura específicamente sobre el análisis del papel del juez constitucional en la lucha contra la pobreza, a partir del examen de la jurisprudencia de la Corte Constitucional de Colombia, con el fin de verificar si -efectivamente- esta corporación ha generado una dinámica de construcción de políticas públicas para combatir la pobreza mediante las reglas jurídicas y órdenes presentes en su jurisprudencia.

Este análisis no pasa por alto el hecho de que le corresponde al poder legislativo el diseño de políticas públicas para combatir la pobreza y al ejecutivo el deber de su ejecución. ${ }^{6}$ No obstante, el punto focal de este estudio consiste en determinar los niveles democratización e inclusividad que incorporan las decisiones judiciales y la adecuación y efectividad con que contribuyen al fortalecimiento de una política pública con enfoque de derechos.

Por consiguiente, la observación que será realizada a partir del contexto del constitucionalismo de la pobreza deberá entenderse como "la influencia decisiva

${ }^{4}$ La Declaración del Milenio, precisamente, parte de esta relación entre pobreza y democracia. NACiONES UNIDAS (2000), párrs. 24-25. Sobre el particular consultar: LEPIANKA (2003) [conceptualiza la relación pobreza y exclusión]; BоTHA (2011) [sobre el concepto de democracia y la representación]; FrASER (2011) [sobre escalas de exclusión].

5 Abramovich y Pautassi (2006), p. 6.

${ }^{6}$ Corte Constitucional de Colombia. Sentencia T-772 de 2003. MP. Manuel José Cepeda Espinosa. 
que el contexto social de la pobreza ejerce sobre el texto constitucional y de este sobre aquella" programas sociales a implementar.

Con este propósito, el siguiente artículo se encuentra dividido en tres partes: en primer lugar, realiza un estudio breve del concepto de políticas públicas; posteriormente, analiza el concepto de judicialización de la política como motor para que el juez constitucional pueda, a través de sus decisiones, fijar elementos para la formulación de políticas públicas y, por último, realiza un amplio estudio jurisprudencial que pretende establecer si la jurisprudencia de la Corte Constitucional de Colombia ha logrado consolidar una política pública de lucha contra la pobreza con enfoque de derechos humanos.

\section{UNA APROXIMACIÓN AL CONCEPTO DE POLÍTICAS PÚBLICAS}

Las políticas públicas comprenden acciones estatales referidas a un "buen uso y práctica del poder a favor de intereses públicos" 8 y que contribuyen a la modernización del Estado toda vez que permiten a través de un proceso de interacción Estado - población "acotar las discusiones políticas, diferenciar problemas y soluciones de manera específica, precisar las diferencias, vincular los temas a soluciones más amplias o secuenciales, plantearse esfuerzos compartidos, participar de manera específica" 9 .

La noción de políticas públicas que adopta el presente análisis es aquella que las define como el conjunto de programas, normas, criterios y reglas de acción, inacción y ejecución que adopta el Estado para la realización a corto, mediano o largo plazo de un fin u objetivo específico:

"Política pública es un proceso integrador de decisiones, acciones, inacciones, acuerdos e instrumentos, adelantado por autoridades públicas con la participación eventual de los particulares, y encaminado a solucionar o prevenir una situación definida como problemática. La política pública hace parte de un ambiente determinado del cual se nutre y al cual pretende modificar o mantener" 10 .

Esta definición es genérica y de ella se derivan elementos cardinales de institucionalidad, acción política y ejecución que son susceptibles de ser concretados

\footnotetext{
7 Cifuentes (1995), p. 57.

8 PNUD (2010), p. 1.

9 Lahera (2004), p. 5. En sentido similar: Marin (2013), pp. 204-205 y Henao (2013), p. 69.

10 Velásquez (2009), p. 156.
} 
en diferentes ámbitos, incluyendo el de las competencias de la administración de justicia frente a la estructuración de políticas públicas en sede judicial ${ }^{11}$.

Para que una política sea pública tiene que contar necesariamente con la participación de autoridades públicas, esto es, con personas e instituciones facultadas expresamente por el ordenamiento jurídico para hacer parte del proceso de formación de las políticas. Las políticas públicas no son exclusivamente las que el presidente de la República y sus ministros, con la participación del Congreso, implementan a nivel nacional. La definición propuesta permite entenderlas como aquellas que se toman en otras áreas de gobierno, por ejemplo en el sector descentralizado de servicios en el nivel departamental o municipal. Así mismo, el Congreso, los organismos de la Rama Judicial, los organismos de control y la Banca Central producen sus propias políticas públicas, en la medida en que el ordenamiento jurídico les permite definir situaciones relevantes o problemáticas para ser enfrentadas ${ }^{12}$.

Partiendo de este punto, la construcción de una política pública en sede judicial debería partir de tener un enfoque de derechos humanos, que constituye una alternativa adecuada para atender de manera efectiva las demandas que surgen de la complejidad que representa el fenómeno de la pobreza, toda vez que colocan a la persona, su dignidad y sus necesidades insatisfechas como eje de su formulación y ejecución en el marco de una dinámica incluyente y participativa. Precisamente, la doctrina más reconocida, ha sostenido que:

En las estrategias de desarrollo y de reducción de la pobreza se ha reconocido ampliamente la importancia de dotar de poder a los sectores pobres y excluidos. El enfoque de derechos humanos apunta esencialmente a ese otorgamiento de poder por la vía del reconocimiento de derechos. Una vez introducido este concepto en el contexto de la adopción de políticas, el punto de partida utilizado para la formulación de una política no consiste en reconocer la existencia de ciertos sectores sociales que tienen necesidades no cubiertas, sino fundamentalmente la existencia de personas que tienen derechos que pueden exigir o demandar, esto es, atribuciones que dan origen a obligaciones jurídicas de parte de otros y por consiguiente al establecimiento de mecanismos de tutela, garantía o responsabilidad ${ }^{13}$.

De lo anterior, puede observarse que el punto de partida de la política pública para combatir la pobreza debe centrarse en el reconocimiento del derecho y es en

11 Aunque genera debate, así ha sido reconocido por otros sistemas jurídicos: Ferejohn (2002), p. 45.

12 Velásquez (2009), p. 163.

13 Abramovich y Pautassi (2006), p. 20. 
ese punto donde el juez está llamado a actuar: a través de sus pronunciamientos dota de contenido a los derechos legalmente consagrados, les da alcance y determina las herramientas que garantizan su realización sustancial.

Sobre esto último, es que se centrará el análisis que se desarrolla en los capítulos siguientes: cómo las órdenes contenidas en providencias judiciales permiten materializar los contenidos de los derechos relacionados con el fenómeno de la pobreza y cómo esas órdenes no sólo se circunscriben a un restablecimiento de derechos para casos particulares, sino que tienen la virtualidad de ser replicadas en casos similares y de incorporarse a las dinámicas de la política social del Estado, lo cual implica una actuación coordinada entre la ramas ejecutiva, legislativa y judicial; no obstante, antes de realizar este estudio, examinaremos de manera breve el concepto de judicialización de la política como elemento contextual, con el objetivo explicar la tendencia actual de intervención de la rama judicial en la construcción de este tipo de políticas.

\section{LA JUdiCIALIZACIÓN DE LA POLÍTICA Y LA LUCHA CONTRA LA POBREZA}

La judicialización de la política puede ser definida como un nuevo modelo en donde se produce una apertura sustancial de los poderes y competencias del juez a ámbitos de acción que no corresponden a aquellos que tradicionalmente les habían sido asignados, pero que, por razones sociales, culturales, económicas o de otra índole demandan su participación como autoridad que reconoce derechos, concreta su alcance y define cuáles podrían ser los mecanismos más adecuados para su realización sustancial mediante un proceso que comprende distintos niveles o fases:

"De acuerdo con Domingo (2004), la judicialización de la política puede definirse siguiendo el análisis de cuatro niveles. En primer lugar, el aumento del impacto de las decisiones judiciales en los procesos políticos y sociales. En segundo lugar, el aumento de la resolución de conflictos políticos en los tribunales. En tercer lugar, en un ámbito más discursivo que, según afirma la profesora boliviana, se refiere a que en la opinión pública la legitimidad del estado se construye cada vez más sobre la base de conceptos legales como rule of law o derechos fundamentales. Por último, la judicialización de la política supone también la utilización, que hacen ciertos grupos de la sociedad, de mecanismos legales para articular, a través de demandas judiciales, distintos intereses económicos, políticos o sociales o vinculados con la protección de los derechos humanos"14.

14 Feoli (2015), p. 81. 
La judicialización de la política implica -entonces- que, asuntos propios de la política-incluidas las políticas públicas-empiezan a ser decididos directamente por los jueces o, por lo menos, a ser objeto de una gran influencia mediante las órdenes contenidas en sus decisiones ${ }^{15}$. En ese sentido, el juez complementa su función de resolver controversias jurídicas con la posibilidad de generar auténticos cambios sociales y políticos con los contenidos de sus decisiones: de hecho, la reciente importancia que se ha reconocido al valor vinculante de los precedentes judiciales y a la necesidad de uniformidad en su aplicación e interpretación muestra como la función judicial ha experimentado un proceso de fortalecimiento que levanta barreras a la actuación judicial ${ }^{16}$. Al respecto, la doctrina más reconocida en la materia, suele señalar que:

Entiendo muy esquemáticamente por judicialización de la política el hecho de que ciertos asuntos que tradicionalmente habían sido decididos por medios políticos, y que se consideraba que eran propios de la política democrática, empiezan a ser crecientemente decididos por los jueces, o al menos son fuertemente condicionados por decisiones judiciales, lo cual implica, a su vez, que muchos actores sociales empiezan a formular sus demandas en términos jurídicos y judiciales. Es claro entonces que esa definición es puramente descriptiva y supone simplemente una modificación de las fronteras tradicionales entre el sistema judicial y el sistema político en las sociedades democráticas, en la medida en que el trámite y la decisión de ciertos asuntos son transferidos de la esfera política al ámbito judicial, con lo cual la dimensión jurídica de la acción social y de la política pública adquiere un mayor peso ${ }^{17}$.

Lo anterior, implica un nuevo modelo de poder judicial que pone todas sus herramientas al servicio de la consecución de la efectividad plena de los derechos humanos, de manera que se reconfigura la actitud institucional tradicional, con un nuevo enfoque hacia la tutela efectiva de los derechos ${ }^{18}$. En ese sentido,

"El modelo institucional del poder judicial y de tribunal constitucional propio del neoconstitucionalismo no es ya una corte moderadora, sino una corte activista. La Corte

15 De Queiroz y Kozicki, p. 60, Ferejohn (2002), pp. 55-56 y De SA y Bonfim (2015), pp. 176-179.

16 En el caso colombiano, por ejemplo, con la entrada en vigencia de la Ley No 1.437 de 2011 las autoridades tienen el deber de aplicar las sentencias de unificación proferidas por el Consejo de Estado, así como las de la Corte Constitucional. Colombia, Ley No 1.437 de 18 de enero de 2011, por la cual se expide el Código de Procedimiento Administrativo y de lo Contencioso Administrativo. Diario Oficial No 47.956 de 18 de enero de 2011.

17 Uprimny (2007), pp. 53-54.

18 Perry (1984), p. 69; Santiago (2008), p. 140. Un debate entre el modelo tradicional y activismo judicial en: BENDOR (2011-2012), pp. 331-337. 
Suprema no aparece tan preocupada por el control de los poderes, por asegurar la división de los mismos como en la promoción y el aseguramiento de los derechos personales ${ }^{19}$.

Por consiguiente, las providencias judiciales mutan su naturaleza y dejan de ser exclusivamente pronunciamientos para dirimir conflictos entre partes, para configurarse como verdaderos instrumentos para lograr la efectividad material de la constitución y la protección de los derechos fundamentales. Así, mediante el nuevo valor reconocido a la jurisprudencia, se permite a los jueces realizar una intervención más amplia en la sociedad para paulatinamente implantar, modificar y dar alcance a determinados valores, principios y normas según las exigencias de la realidad.

Aunque -en ocasiones- este fenómeno suele referirse con el concepto de activismo judicial, para los efectos de este artículo deberá entenderse que la judicialización de la política puede requerir una cierta disposición de los jueces por solventar necesidades sociales, siempre en el marco del Estado de derecho, es decir, sin necesidad de tomar decisiones políticas como consecuencias de una crisis del sistema ${ }^{20}$.

En este punto, vale la pena preguntarse ¿qué es aquello que legitima al juez para actuar más ampliamente? ¿Con qué herramientas cuenta el juez, en especial el juez constitucional, para legitimarse y asumir un nuevo rol? ¿Qué factores permiten hacer referencia a dinámicas de judicialización de la política?

$\mathrm{Al}$ respecto, tal como lo indica el profesor Sierra, dos nociones esenciales son las que legitiman al juez para expandir el ámbito de ejercicio de sus competencias: el interés general y la eficiencia. El interés general que permite "construir una cierta idea de interés público capaz de garantizar el principio de igualdad dentro de la sociedad" 21 y la eficiencia que otorga legitimidad al Estado, ya que materializa la noción de interés general ${ }^{22}$.

Estas dos nociones complementarias se relacionan directamente con la labor judicial, toda vez que el juez -constitucional- a través de sus competencias interpretativas contribuye a que se pongan en marcha políticas públicas eficientes que respondan a las demandas sociales, económicas y culturales que se plantean cotidianamente en el marco de un Estado Social de Derecho ${ }^{23}$. Bajo esta óptica, el juez constitucional es un actor que contribuye a materializar y cumplir las políticas

19 Santiago (2008), p. 142.

20 La diferencia entre estos dos conceptos en: De SA y Bonfim (2015), pp. 179-180.

21 Sierra (2009), p. 41.

22 Ibíd., p. 39.

23 Ibíd., p. 40. 
públicas en la medida en que el derecho constitucional -sobre el que reposan todas las estructuras jurídicas y políticas del Estado-, le confiere legitimidad y herramientas para ampliar sus competencias, dotando de orden y contenido las normas y derechos que hacen parte del ordenamiento jurídico. En tal sentido, la jurisprudencia constitucional sienta importantes parámetros en materia de justicia distributiva que deben ser adoptados por los organismos estatales encargados de ejecutar la política social del Estado, de modo tal que, la interpretación constitucional termina orientando la ejecución de las políticas públicas.

"Y allí, en un nivel de complejidad, el derecho constitucional, en cuanto el universal de lo jurídico y en cuanto un derecho global y total de interpretación de toda la estructura social, surge como instrumento responsable de organizar tal dispersión, ya que, bajo el poder de interpretación y protección de las libertades públicas y de garantía de la separación de los poderes, posee una importancia que lo hace determinante dentro de los nuevos desarrollos y desafíos del Estado y de las demandas sociales (...) La administración de misión, la protección de los derechos fundamentales, y la garantía de la separación de los poderes en el espacio administrativo o político le otorgan al juez constitucional el poder y la legitimidad de orientar la acción pública y arbitrar la pluralidad de los intereses sectoriales" 24 .

Así, la posición que asuman los jueces en el marco de judicialización de la política con enfoque de derechos humanos será determinante para reivindicar la condición de quienes se encuentran en situaciones de especial vulnerabilidad. En ese sentido, las situaciones deficitarias que afectan la debida materialización y garantía de los derechos, se presentan como habilitaciones para que el juez pueda ordenar su restablecimiento y, por esa vía, lograr que las autoridades administrativas concreten programas e instauren políticas que les doten de plena exigibilidad ${ }^{25}$.

"Se transforma, entonces, el juez en un actor que detenta la capacidad de definir la forma de distribución de los bienes sociales, y de garantizar límites a los derechos en el momento de regular la estructura normativa de las políticas públicas y de realizar la readecuación interpretativa de la norma jurídica desde el análisis jurisprudencial de los antecedentes y los límites a los principios constitucionales.

Esto significa que la jurisprudencia constitucional construye un concepto distributivo de bienes sociales al momento de analizar las estructuras normativas de la acción

24 Ibíd., pp. 45 y 49.

25 Henao (2016), p. 75. 
pública, respecto del marco y los principios constitucionales. Es un proceso de adecuación constitucional de la acción y la decisión administrativa"26.

Para el caso que nos ocupa, la intervención que realiza la Corte Constitucional de Colombia lleva de forma implícita las siguientes potestades en materia de judicialización de la política pública:

(i) canaliza los requerimientos y necesidades insatisfechos de la ciudadanía al tramitar demandas de inconstitucionalidad y admitir la revisión de sentencias de tutela (art. 241 de la Constitución Política);

(ii) determina el objeto de la protección invocada por la ciudadanía e involucra a las entidades (estatales o sujetos particulares) requeridas para que expresen su posición al respecto y justifiquen su modo de proceder frente a un caso concreto;

(iii) da alcance a los derechos cuya protección se invoca y pone de manifiesto qué tipo de actuaciones - del Estado o de los particulares- son las que desconocen el contenido de los derechos y degeneran en la insatisfacción de necesidades elementales y

(iv) profiere órdenes tendientes al restablecimiento adecuado del contenido de los derechos que, por su contenido y alcance, pueden constituir decisiones de política pública.

Teniendo en consideración lo anterior, el punto se encuentra en determinar cómo la Corte Constitucional a través de su jurisprudencia ha logrado que se materialicen por otras autoridades auténticas políticas en materia de pobreza. Con este objetivo, el presente documento realiza un amplio análisis jurisprudencial, que será desarrollado en el acápite siguiente.

\section{Análisis de la jurisprudencia de la Corte Constitucional de COLOMBia y LA POLÍTICA PÚBliCA EN MATERIA DE POBREZA (1991-2015)}

\subsection{Metodología}

Una vez revisado el marco conceptual de este estudio, el principal objetivo de esta investigación consiste en realizar un análisis de la jurisprudencia proferida por la Corte Constitucional desde 1991 a 2015 en materia de pobreza. Para tal fin, se analizó una muestra representativa de 56 sentencias (incluye autos de seguimiento), en donde el proceso de selección consistió en (a) la observancia de un criterio formal (la titulación de las providencias) y (b) un criterio sustancial

26 Sierra (2009), p. 64. 
(la búsqueda de contenidos referidos a la dignidad humana como condiciones materiales mínimas de existencia) para filtrar las providencias a examinar.

El estudio comprende un análisis de: (i) la tipología de providencias adoptadas, (ii) los sujetos protegidos, (iii) los derechos tutelados, (iv) las decisiones tomadas y en especial, del contenido de las órdenes proferidas porque es allí donde podrá determinarse cuál ha sido el alcance de la incidencia de la jurisprudencia constitucional en la ejecución de políticas públicas para combatir efectivamente la pobreza.

\subsection{Tipología de sentencias proferidas en relación con la pobreza}

\section{llustración 1 - Tipología de providencias}

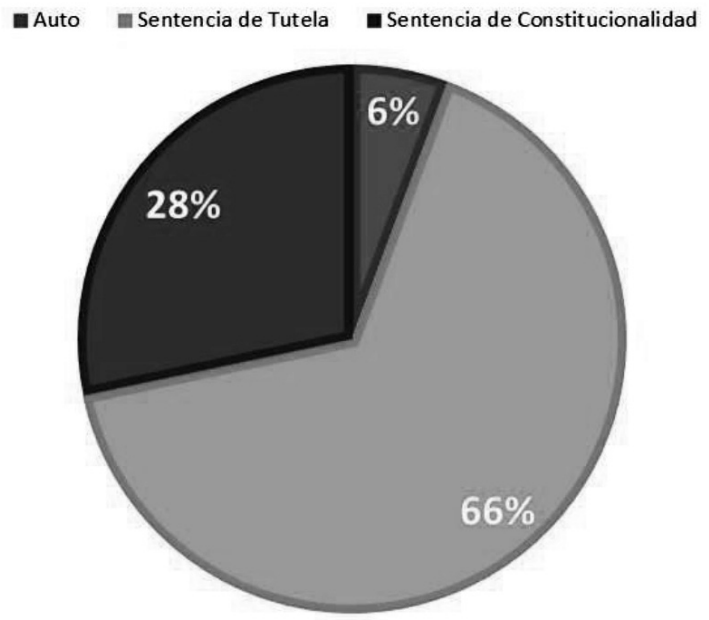

Fuente: Elaboración propia.

Como puede apreciarse del universo de providencias analizadas (56), un 66\% corresponde a sentencias de tutela, en tanto que las sentencias de constitucionalidad ocupan un lugar secundario con un $28 \%$ y los autos de seguimiento una posición mínima correspondiente a un $6 \%$.

$A$ priori, se puede ver que el desarrollo jurisprudencial relacionado con la pobreza se realiza analizando casos concretos -peticiones de tutela en sede de revisión-. Esto permite señalar que el acercamiento del tribunal constitucional se centra en brindar soluciones específicas. Por consiguiente, podría señalarse que parte de un enfoque de derechos humanos, toda vez que la protección no se realiza a partir de un análisis abstracto de constitucionalidad de normas jurídicas -con efectos generales y poco medibles- sino desde la complejidad multipolar del 
fenómeno de la pobreza que afecta a ciudadanos en contextos específicos. Este análisis nos permite realizar tres afirmaciones relacionadas con los elementos de las políticas públicas en sede judicial:

(i) El análisis realizado muestra la importancia capital de la participación ciudadana, en el sentido de que el ciudadano común tiene la posibilidad de acudir directamente al Tribunal Constitucional -en sede de revisión de tutela- para solicitar la protección de sus derechos fundamentales.

(ii) La Corte Constitucional de Colombia genera dinámicas de acercamiento judicial con la ciudadanía al tener competencia para conocer de acciones públicas e informales, que dan lugar a la consolidación de un importante elemento de especificidad para el estudio y resolución de casos concretos. Lo que le permite conocer de forma específica las circunstancias sociales, económicas, culturales y jurídicas a las cuales se pretende dar solución.

(iii) Se hace patente la perspectiva de derechos humanos que debe orientar la construcción de políticas públicas en sede judicial, toda vez que los asuntos sometidos a su conocimiento tienen una naturaleza fundamental que exige el reconocimiento y la garantía de los derechos a la igualdad y a la dignidad humana.

A pesar de lo anterior, resulta relevante señalar que dentro de este análisis no se localizaron Sentencias de Unificación -con efectos inter comunnis-, con lo cual se facilitaría la uniformización de precedentes en materia de pobreza y, por tanto, de las órdenes que se deben proferir. Precisamente, la forma como se ha construido la jurisprudencia, en principio, no permitiría consolidar verdaderos programas sociales con elementos de focalización y, por el contrario, podría generar mecanismos de desigualdad, toda vez que estaría respondiendo a las expectativas de unos pocos afortunados que logran que sus casos sean revisados por este tribunal.

\subsection{Principales temáticas abordadas en relación con la pobreza}

El presente acápite tiene por objetivo presentar los principales temas abordados en las sentencias de constitucionalidad y de tutela proferidas por la Corte Constitucional de Colombia en materia de pobreza. Esto permite, por un lado, observar la complejidad multipolar del fenómeno de la pobreza que incorpora una gran cantidad de matices y, en segundo lugar, determinar cuáles de estos han sido abordados por la jurisprudencia a partir de la interposición de acciones públicas. ${ }^{27}$

27 Para observar en mayor detalle las temáticas tratadas por la Corte Constitucional revisar anexo I de la presente investigación. 


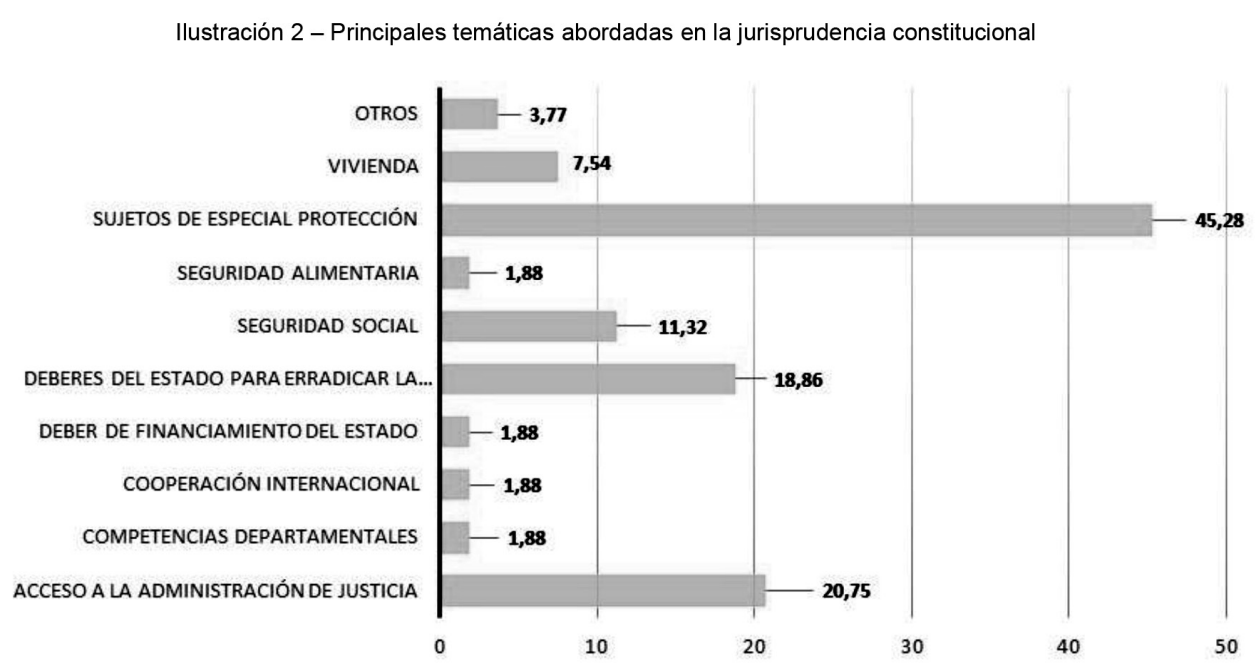

Fuente: Elaboración propia.

Esta ilustración pone de manifiesto que el tema que ha tenido mayor incidencia es el relacionado con las personas consideradas como sujetos de especial protección constitucional, es decir, aquellos sujetos que por sus condiciones personales, sociales y económicas son más vulnerables ante la sociedad y requieren de una protección reforzada. Este conjunto de sujetos comprende niños, ancianos, mujeres, entre otros, cuyo estudio se abordará de forma detallada en el acápite siguiente.

En segundo lugar, la temática con mayor incidencia es la relacionada con el acceso a la administración de justicia de aquellas personas que se encuentran en situación de pobreza; si bien la Constitución Política de Colombia reconoce que la rama judicial se rige por el principio de gratuidad, es claro que el acceso a la misma implica algunos gastos y erogaciones que en muchas ocasiones las personas no se encuentran en capacidad económica o material de sufragar. Por ello, se ha reconocido la institución procesal del amparo de pobreza como una herramienta fundamental para garantizar el derecho de acceso a la administración de justicia de aquellas personas que se encuentran en situación de pobreza y desposeimiento, de manera que no solo se materializan los principios de equidad y de justicia, sino que por esa vía se fomenta la participación ciudadana en la modalidad de accesibilidad a las instituciones estatales.

En tercer lugar, la jurisprudencia analizada reconoce una serie de obligaciones para el Estado, las instituciones y las autoridades públicas para conjurar el fenómeno de la pobreza. Entre estos deberes se encuentra el de implementar planes, 
políticas públicas y programas sociales que contribuyan a mitigar los efectos de la pobreza y a erradicar sus causas de forma progresiva.

Este punto es esencial, porque en él se encuentra el fundamento de la legitimidad de la Corte Constitucional para intervenir en materia de política pública. Precisamente, las acciones u omisiones constitutivas de incumplimiento del deber social del Estado de conjurar las causas y efectos de la pobreza, ha sido la causa que justifica la intervención del juez constitucional en la formulación de programas sociales y políticas públicas.

Por su parte, se localiza en cuarto lugar el tema de la seguridad social en salud y pensiones. Esta temática constituye uno de los pilares fundamentales para garantizar condiciones de vida digna en materia de pensiones y salud a la población en condición de pobreza, toda vez que les garantiza un ingreso mínimo durante la época de la jubilación y el acceso a servicios médicos a través de un régimen subsidiado. El sistema de seguridad social hace parte de los sistemas de protección con que los Estados garantizan condiciones mínimas de dignidad en ingresos y salud a las personas, más aún cuando estas se encuentran en situaciones de pobreza. En ese sentido, el sistema de seguridad social es foco de políticas públicas articuladas y coordinadas para la materialización de los programas sociales, con enfoque proactivo y de derechos humanos porque exige la contribución -mínima y proporcional- de los usuarios para acceder a sus beneficios.

Por otro lado, es preocupante que asuntos de trascendencia como la vivienda, la cooperación internacional para el desarrollo y la asignación de competencias departamentales para combatir la pobreza ocupen un lugar residual dentro de las providencias analizadas, toda vez que corresponden a situaciones de actualidad que demandan mayor intervención del juez constitucional; es más, son temáticas que incorporan dos elementos esenciales que constituyen parte del objeto de toda política pública en materia social: la redistribución de bienes e ingresos y la asignación coordinada y eficiente de competencias a nivel nacional (a entidades territoriales) para combatir la pobreza en todo nivel.

Finalmente, todas las temáticas analizadas ponen de manifiesto otro de los elementos de las políticas públicas: la focalización y priorización de la intervención, en este caso del juez constitucional, en determinadas áreas problemáticas conforme a las demandas y requerimientos de la ciudadanía. Esta focalización además se complementa con los sujetos que se ven protegidos por las reglas y órdenes jurisprudenciales y cuyo análisis se presenta a renglón seguido. 


\subsection{Sujetos de protección por parte de la Corte Constitucional}

En este acápite se realiza un análisis de los beneficiarios de las decisiones proferidas por el tribunal constitucional: las personas, los sujetos destinatarios de las políticas públicas, que representan ante la Corte Constitucional de Colombia a los sectores más agobiados por la pobreza y, a la vez, encarnan la multipolaridad del fenómeno teniendo en cuenta a la diversidad cultural, social y generacional de personas a las que afecta.

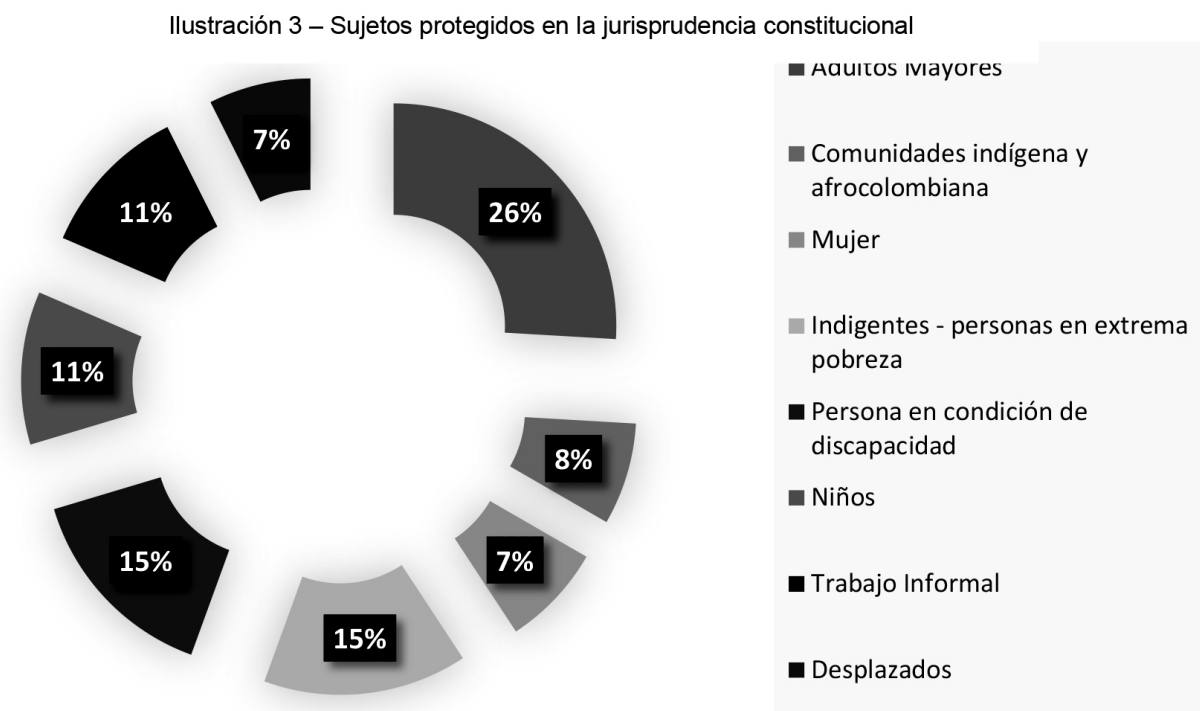

Fuente: Elaboración propia.

Conforme al análisis efectuado, la mayor protección judicial ha sido recibida por las personas de la tercera edad, cuya especial condición de vulnerabilidad ha sido reconocida en el $26 \%$ de los casos estudiados, donde se ha fijado el carácter reforzado de la protección a la que son acreedores como consecuencia de la disminución sustancial de sus capacidades, que se ve agravada en circunstancias donde las carencias materiales afectan derechos como el mínimo vital, la salud, la vivienda digna, entre otros. Ello se ha manifestado de forma especial en el derecho que tienen las personas de la tercera edad a la seguridad social y a la asistencia pública en casos de extrema pobreza ${ }^{28}$.

$28 \mathrm{Al}$ respecto se puede consultar: Corte Constitucional de Colombia. Sentencia T-495 de 1997. M. P. Carlos Gaviria Díaz. 
Llama la atención el especial esfuerzo que ha desplegado la Corte Constitucional en el caso de los ancianos que se encuentran en situación de indigencia, poniendo de manifiesto que su situación de desposeimiento y abandono por parte de la sociedad es altamente reprochable y, por tanto, han de tomarse todas las medidas necesarias para mitigar su situación socioeconómica. Más adelante se realizará un análisis del tipo de órdenes proferidas al respecto, pero por ahora, se puede hablar de un importante elemento de focalización, propio de políticas públicas que buscan conjurar las necesidades de un grupo poblacional determinado.

El nivel subsiguiente de protección se encuentra ocupado por personas que se encuentran en situación de extrema pobreza -indigencia- y en condición de discapacidad, cada uno con un índice del 15\%. Al respecto, frente a las personas en condición de discapacidad, la Corte ha reconocido que el Estado se encuentra en el deber de cumplir una serie de obligaciones prestacionales que garanticen su inclusión en la sociedad, le garanticen su derecho a la igualdad formal y material y, por esa vía, le permitan subsistir de la manera más autónoma y digna posible, procurando solventar en la mayor medida su situación de desposeimiento material que se ve agravada por su estatus físico o psicológico ${ }^{29}$.

$\mathrm{Al}$ mismo tiempo, ha señalado que las personas que se encuentran en situación de indigencia -por su alta marginación y vulnerabilidad- requieren del Estado la aplicación de los principios de equidad y solidaridad para reivindicar su humani$\mathrm{dad}^{30}$. Precisamente, el tribunal constitucional ha indicado que

"La sociedad no puede asumir una actitud de desprecio o de pasiva conmiseración hacia quienes, por fuerza de las circunstancias, llevan una vida sub-normal y altamente lesiva del derecho a la igualdad que pregona la Carta. Su papel y muy especialmente el del Estado debe ser, por el contrario, el de buscar, dentro del criterio de solidaridad, soluciones eficaces y urgentes a la problemática que plantea la proliferación de cinturones de miseria en las ciudades, ya que el artículo 13 de la Constitución le ordena, como atrás se dijo, promover las condiciones para que la igualdad sea real y efectiva y adoptar medidas en favor de grupos discriminados o marginados"31.

29 Corte Constitucional de Colombia. Sentencia T-608 de 2007. M. P. Rodrigo Escobar Gil.

30 "Sus causas estructurales son combatidas mediante políticas legislativas y macroeconómicas. Sus efectos, en cambio, exigen de una intervención estatal directa e inmediata, cuyo fundamento no es otro que la naturaleza social del Estado y la efectividad de los principios, derechos y deberes consagrados en la Constitución”. Corte Constitucional de Colombia. Sentencia T-1098 de 2008. M. P. Clara Inés Vargas Hernández.

31 Corte Constitucional de Colombia. Sentencia T-523 de 2006. M. P. Clara Inés Vargas Hernández. 
En relación con los niños, que tienen un índice del 11\%, la jurisprudencia constitucional ha hecho especial énfasis en la protección reforzada de las que son sujetos en razón de la prevalencia de sus derechos por expresa disposición constitucional (artículo 44). Por este motivo, los temas de mayor relevancia en relación con la dignidad de los niños se refieren (i) a las condiciones de pobreza que se reflejan en los obstáculos de diferente índole para acceder al sistema de educación ${ }^{32}$ o (ii) a la condición socio económica de su familia, en aquellos casos donde debe ponderarse entre el derecho a la familia y el derecho a unas condiciones de vida digna que justifiquen la separación del niño de su entorno ${ }^{33}$.

Por su parte, en relación con la situación de los trabajadores informales, la jurisprudencia constitucional ha reconocido que las altas tasas de desempleo que agobian a ciertos sectores del país fuerzan a las personas a acudir a otros medios de trabajo que les permitan obtener su sustento diario. Por ello, no se les puede privar arbitrariamente de esos medios de subsistencia y, en aquellos casos en que sea absolutamente necesario, se ha señalado que deben existir políticas o programas sociales que permitan la inserción a otros medios de producción, en especial, en el caso de los vendedores ambulantes que son desalojados de sus puestos de trabajo en razón de políticas de recuperación del espacio público ${ }^{34}$.

Respecto de las comunidades étnicas, la jurisprudencia ha reconocido las condiciones de marginalidad social, cultural, política y económica a la que históricamente se han visto sometidas y ha establecido la obligación de brindar medios adecuados de inclusión y participación democrática que permitan conjurar esa situación de aislamiento, a través de la aplicación de políticas de discriminación positiva, que las sitúe en igualdad de condiciones que las demás personas, ${ }^{35}$ con lo cual se materializa el enfoque de derechos humanos en la construcción de políticas públicas, pasando del asistencialismo a la democratización y la construcción proactiva de programas sociales.

Finalmente, en relación con la situación de la mujer, la Corte Constitucional de Colombia no ha sido demasiado específica, toda vez que su condición es susceptible de ser incluida dentro de todas las categorías de sujetos que vienen de estudiarse, sin embargo, de manera reiterada la jurisprudencia ha reconocido

\footnotetext{
32 Corte Constitucional de Colombia. Sentencia T-612 de 2006. M. P. Nilson Pinilla Pinilla.

33 Corte Constitucional de Colombia. Sentencia T-510 de 2003. M. P. Manuel José Cepeda Espinosa.

34 Corte Constitucional de Colombia. Sentencia T-773 de 2007. M. P. Humberto Antonio Sierra Porto.

35 Corte Constitucional de Colombia. Sentencia C-169 de 2001. M. P. Carlos Gaviria Díaz.
} 
que se trata de personas que -como tales- son merecedoras de una protección especial y que su situación de vulnerabilidad aumenta cuando están sometidas a graves condiciones de desposeimiento y pobreza.

\subsection{Decisiones adoptadas en sede de control abstracto de constitucionalidad}

Dentro del análisis de adecuación constitucional de las normas jurídicas cuyo conocimiento es competencia de la Corte Constitucional, lo que se pone de manifiesto en materia de pobreza es que una amplia mayoría (61\% de las leyes demandadas) son declaradas exequibles, lo cual permite afirmar que en este complejo ámbito social el legislador ha actuado de manera ajustada a la Constitución en la regulación de políticas y programas sociales para combatir la pobreza.

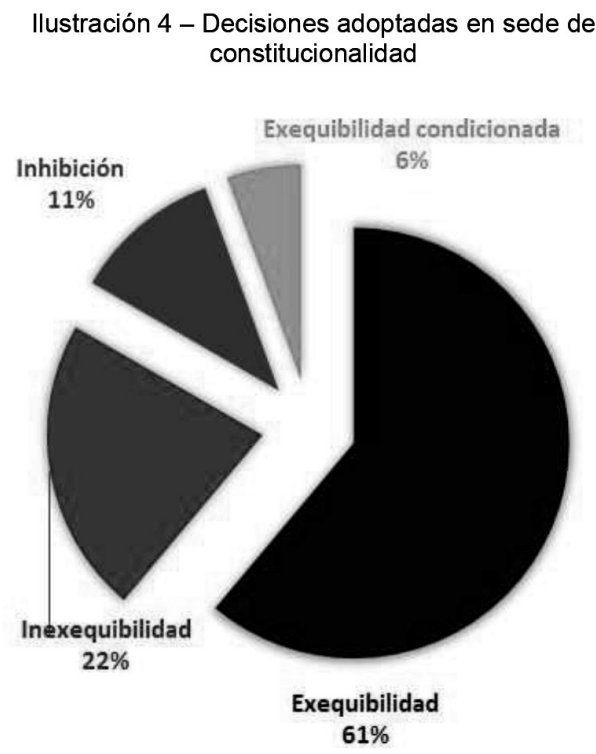

Fuente: Elaboración propia.

Sin embargo, a pesar de los resultados, es menester preguntarse si ha actuado de manera suficiente y eficaz para garantizar la equidad, el bienestar social y la efectividad de los derechos de aquellas personas que se encuentran en situaciones de desposeimiento y vulnerabilidad.

Así mismo, vale la pena cuestionarse acerca del alcance del contenido de las leyes y de las políticas públicas bajo el enfoque de los derechos humanos, es decir, se debe verificar si su alcance se limita al asistencialismo puro o si, por el contrario, se promueve la democratización en la elaboración de soluciones conjuntas y coordinadas 
para la satisfacción de las necesidades de los distintos grupos sociales en situación de pobreza. En este sentido, la posición adoptada en la presente investigación, entiende que no basta sólo en estos casos la adecuación de la ley al texto constitucional, sino la eficacia práctica de la misma y de las políticas públicas en ella contenidas.

Ahora bien, frente a la tipología de decisiones en sede de constitucionalidad puede afirmarse, en primer lugar que, en materia de declaratoria de exequibilidad, la Corte Constitucional de Colombia no ha actuado como actor de políticas públicas porque solo se ha limitado a verificar la conformidad de normas con el ordenamiento jurídico y a declarar dicha adecuación constitucional. A pesar de lo anterior, ha sentado reglas jurisprudenciales y precedentes importantes que permiten orientar el contenido de las políticas públicas planteadas por el legislador hacia el enfoque de los derechos humanos; sin embargo, en las órdenes proferidas no existe un contenido propio de una política pública para combatir la pobreza.

\subsection{Decisiones adoptadas en sede de revisión de sentencias de tutela}

Como puede observarse, la jurisprudencia constitucional en los casos que involucran el fenómeno de la pobreza ha demostrado una tendencia amplia hacia el garantismo y la protección de los derechos fundamentales en sede de revisión: en un $83 \%$ de los casos, la Corte Constitucional de Colombia ha procedido a revocar providencias de otras instancias judiciales y ha garantizado la tutela efectiva de los derechos fundamentales.

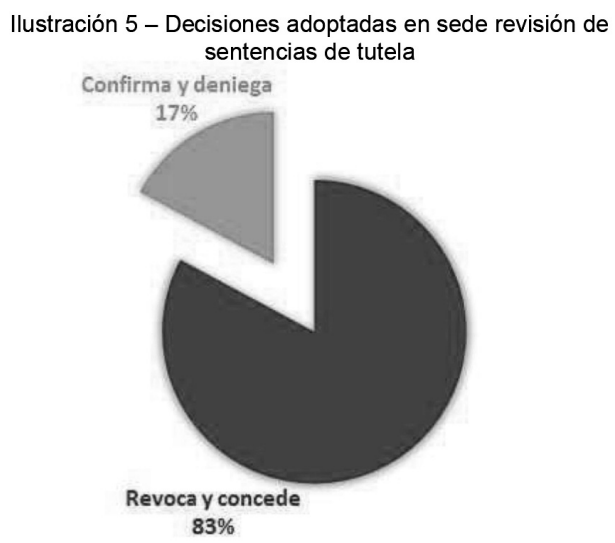

Fuente: Elaboración propia.

Dentro del 17\% restante, se encuentran aquellos casos en que la Corte confirma las providencias de otras instancias judiciales y deniega la protección en sede de revisión de los derechos fundamentales como consecuencia bien sea de factores procesales -subsidiariedad, legitimación, inmediatez, etc.- o de factores 
sustantivos -que se relacionan directamente con el contenido de la decisión objeto de revisión- que hacen innecesaria la intervención del máximo tribunal Constitucional.

Lo anterior es esencial, porque pone de manifiesto el potencial que tiene la Corte Constitucional de Colombia, de suplir las falencias en que han incurrido otras autoridades judiciales, lo cual es importante porque le faculta para la adopción de órdenes adecuadas para la tutela judicial efectiva de los derechos afectados a consecuencia del fenómeno multipolar de la pobreza. Precisamente, aquí se encuentra un punto básico para la legitimación de la Corte Constitucional como actor judicial de políticas públicas en materia de pobreza: la posibilidad de suplir falencias judiciales.

\subsection{Derechos tutelados en sede de revisión de sentencias de tutela}

Ilustración 6 - Derechos amparados en sede de revisión de sentencias de tutela

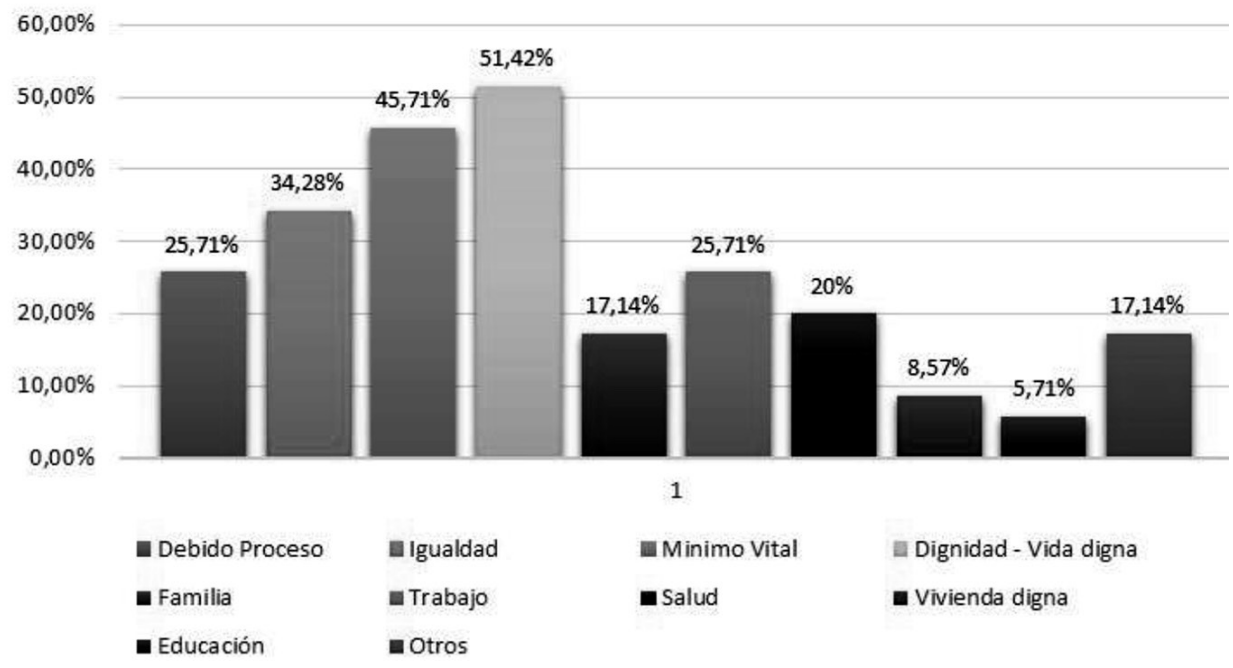

Fuente: Elaboración propia.

Como se puede observar, los derechos que con mayor frecuencia son objeto de protección en sede de revisión son la dignidad humana con un índice del 51,42\%, el mínimo vital con un $45,71 \%$ y la igualdad en un $34,28 \%$. En ese sentido, es posible observar como en los tres primeros lugares de incidencia los requerimientos de la población en situación de pobreza se refieren al restablecimiento de los derechos fundamentales básicos, ya que la dignidad, como eje del ordenamiento jurídico junto con el mínimo vital y la igualdad, constituyen presupuestos esenciales no 
sólo del desarrollo integral de la persona, sino de los objetivos cardinales sobre los que se deben construir las políticas públicas en materia de lucha contra la pobreza.

En ese sentido, frente al alcance de estos derechos, la Corte ha considerado que, en relación con la dignidad, esta constituye el elemento esencial sobre el cual se edifica el concepto de Estado Social de Derecho, lo cual implica la necesidad de brindar una especial protección a quienes por su condición se encuentran en circunstancias de vulnerabilidad, como es el caso de las personas en situación de pobreza extrema. ${ }^{36}$

Frente al derecho al mínimo vital, la jurisprudencia constitucional ha establecido que su alcance está dado por "aquellos "requerimientos básicos indispensables para asegurar la digna subsistencia de la persona y de su familia", especialmente, en lo relacionado con su alimentación, vestido, educación, vivienda y seguridad social. Así mismo, ha precisado que el mínimo vital es una

"institución de justicia elemental que se impone aplicar, como repetidamente lo ha hecho la Corte Constitucional, en situaciones humanas límites producidas por la extrema pobreza y la indigencia cuando quiera que frente a las necesidades más elementales y primarias, el Estado y la sociedad no responden de manera congruente y dejan de notificarse de las afectaciones más extremas de la dignidad humana" 37

En lo que se refiere al derecho a la igualdad ha señalado que, en el marco del Estado Social de Derecho, constituye el norte de las actuaciones de las autoridades públicas, con el fin de corregir la inequidad social y promover la participación y la inclusión de las personas que se encuentran en especial situación de vulnerabilidad para mejorar progresivamente sus condiciones de existencia ${ }^{38}$.

Es necesario resaltar que el carácter iusfundamental de los tres derechos cuya protección se reclama con mayor frecuencia, junto con el alcance que la Corte

\footnotetext{
36 Corte Constitucional de Colombia. Sentencia T-207 de 2013. M. P. Jorge Iván Palacio Palacio.

37 Corte Constitucional de Colombia. Sentencia T-651 de 2008. M. P. Clara Inés Vargas Hernández.

38 “...las autoridades están obligadas, en primer lugar, a promover por los medios que estimen conducentes la corrección de las visibles desigualdades sociales de nuestro país, para así facilitar la inclusión y participación de los débiles, marginados y vulnerables en la vida económica y social de la nación, y estimular un mejoramiento progresivo de las condiciones materiales de existencia de los sectores más deprimidos de la sociedad - que día a día se multiplican, y de hecho conforman, actualmente, la mayoría poblacional-: "la interpretación sistemática del principio fundamental del Estado Social de Derecho y de los preceptos constitucionales que lo concretan, permite concluir que dicho principio abarca, sin caer en el paternalismo o en el asistencialismo, contenidos tanto de participación en la prosperidad general, de seguridad frente a los riesgos de la vida en sociedad, de equiparación de oportunidades como de compensación o distribución de cargas. Por la concepción material de la igualdad, el grado y tipo de protección requerido varía entre situaciones diferentes, cuando se trata de distribuir y asignar recursos escasos en un contexto en el que existen objetivamente necesidades insatisfechas que el Estado debe prioritariamente atender..”.. Corte Constitucional de Colombia. Sentencia T-772 de 2003. M. P. Manuel José Cepeda Espinosa.
} 
Constitucional les ha reconocido, refuerza el enfoque de derechos humanos para la construcción de políticas públicas contra la pobreza, toda vez que el contenido que se reconoce a estas categorías de derechos es el factor central que delimita las órdenes tendientes a su restablecimiento.

Por su parte, el análisis realizado muestra que las categorías de derechos que siguen en orden de justiciabilidad son los que académicamente corresponden a la categoría de derechos económicos, sociales y culturales (en adelante DESC), tales como la seguridad social, el trabajo y la educación ${ }^{39}$. En ese sentido, lo que se pone de manifiesto - nuevamente- es la complejidad multipolar del fenómeno de la pobreza, que exige la implementación de políticas públicas y programas sociales con carácter progresivo (propias de esta categoría de derechos).

\subsection{Tipología de órdenes adoptadas en sede de revisión}

En el gráfico que se observa a continuación, se encuentran sistematizadas las principales órdenes que han sido proferidas en sede de tutela para conjurar la amenaza o vulneración a los derechos fundamentales de aquellas personas que se encuentran en situación de pobreza. Este punto es de capital importancia, no sólo porque muestra las problemáticas que han sido abordadas por la jurisprudencia constitucional en la lucha contra la pobreza, sino porque, a su vez, materializa el tipo de herramientas que la Corte Constitucional de Colombia ha utilizado en la defensa de los derechos fundamentales afectados por el fenómeno de la pobreza.

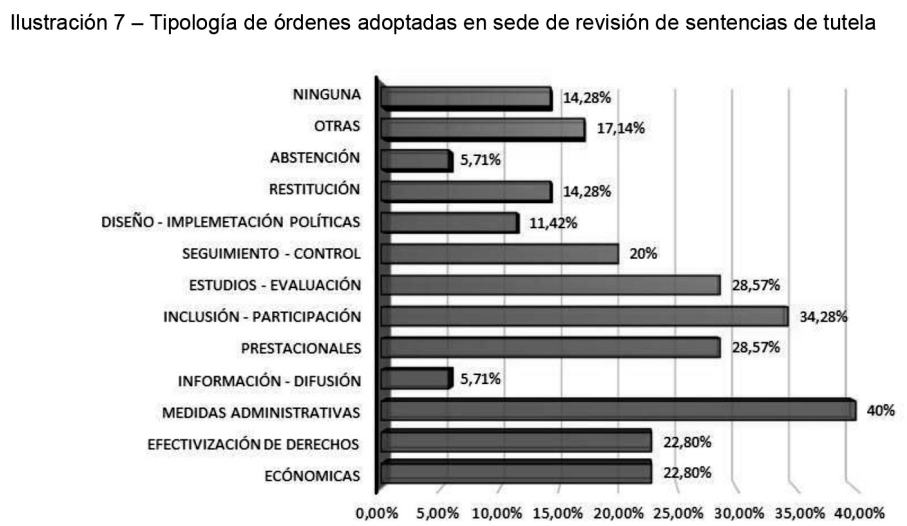

Fuente: Elaboración propia.

39 El debate sobre la justiciabilidad de estos derechos se puede observar en: FiguerOA (2009). 
De conformidad con el análisis realizado, las órdenes muestran una tipología diversa que responde de forma directamente proporcional a la multiplicidad de problemas que encarna el fenómeno de la pobreza: es decir, a mayor complejidad en un caso concreto, mayor diversidad en las órdenes proferidas para conjurar las diversas aristas o cuestiones que le son innatas. Sin embargo, en materia de políticas públicas formuladas en sede judicial, esto debe ser interpretado con reserva, si se tiene en cuenta que si bien las órdenes son diversas, el tribunal constitucional sólo puede emitir pronunciamientos en aquellos casos que llegan a su conocimiento.

Ahora bien, dentro de esta limitación, se evidencia que las órdenes principales corresponden a la toma de medidas administrativas en un $40 \%$ de los casos, alto porcentaje que se puede analizar desde dos perspectivas diferentes: (i) como regla general a manera de exhorto que hace la Corte Constitucional para que la autoridades administrativas vinculadas a un caso concreto tomen las medidas necesarias en el ámbito de su competencia y (ii) en casos excepcionales en los que actúa como gestor directo de medidas que luego habrá de ejecutar la autoridad administrativa que ha incurrido en alguna falencia y que -en razón de esto- faculta al tribunal a intervenir como actor de políticas públicas.

Lo anterior es de capital importancia porque muestra que -en principio-, el tribunal constitucional busca mantener los cauces de su actuación en el marco de las competencias que le han sido atribuidas constitucional y legalmente, de forma tal que la administración pública siempre será la primera en ser llamada para la ejecución de medidas de lucha contra la pobreza, salvo que se presenten graves falencias administrativas que legitimen su intervención.

En segundo lugar, se encuentran otro tipo de órdenes relacionadas con mecanismos de inclusión y participación que corresponden al 34,28\% de los casos. Estas medias son vitales porque contribuyen a la materialización del enfoque de derechos humanos que debe fundamentar las políticas públicas, toda vez que propende hacia la participación activa de los beneficiarios y ello es esencial porque democratiza la política y la hace eficiente en un esquema altamente proactivo. Así mismo, las órdenes de participación acercan al juez al conocimiento de las necesidades de la población en situación de pobreza, haciéndolas más humanas y menos abstractas ${ }^{40}$. Estas medidas implican per se el abandono del asistencia-

40 En la mayoría de los casos, estas órdenes han sido proferidas en materia de trabajo informal, donde la sentencia T-772 de 2003 constituye un gran ejemplo de este tipo de órdenes que llaman a la inclusión y a la participación ciudadana en los procesos constructivos de política pública. 
lismo en materia de políticas públicas, para dar paso a la democratización en su construcción, gestión, ejecución y evaluación.

En tercer lugar, se encuentran las órdenes de carácter prestacional proferidas en un $28,57 \%$ de los casos y que incorporan un contenido esencialmente económico, toda vez que conllevan el reconocimiento y pago de determinadas sumas de dinero con el fin de morigerar la situación grave de desposeimiento de aquellos sujetos que acuden jurisdicción. Bajo este parámetro, el tribunal constitucional actúa como un orientador del gasto público social, toda vez que da directrices claras y vinculantes a las autoridades administrativas para proceder al desembolso e inversión de recursos financieros en la lucha contra la pobreza.

Estas órdenes comprenden el pago de prestaciones económicas pendientes, como subsidios o pensiones, que de no ser percibidos afectarían gravemente el derecho al mínimo vital y a la dignidad ${ }^{41}$. No obstante, es necesario aclarar que si bien el contenido prestacional en la mayoría de los casos tiene un carácter económico ( $22,8 \%$ de los casos), éste no es exclusivo, ni excluyente, toda vez que las órdenes -también- abarcan otro tipo de prestaciones de bienes y servicios $v$. gr. entrega de medicinas y alimentos, que contribuyen a morigerar la situación de desposeimiento y vulnerabilidad ${ }^{42}$.

Aunque estos mecanismos de protección son importantes porque representan una solución clara y exigible, consideramos que son propios del asistencialismo clásico, ya que sólo implican obligaciones de dar y hacer, pero obvian la participación de los sujetos en la solución de sus necesidades. Puede que por razones de eficacia y practicidad la orden se profiera sin previa consulta de los afectados, no obstante, desde el plano de construcción de una política pública con enfoque de derechos humanos, este comportamiento debe ser calificado como inaceptable.

41 Un ejemplo se encuentra en la sentencia T-648 de 2008, que dispuso lo siguiente: "Tercero.- Ordenar a la Dirección Seccional de Salud de Antioquia, que dentro del término de las cuarenta y ocho (48) horas siguientes a la notificación de esta sentencia, si aún no lo hubiere hecho, autorice y efectúe el pago de las cuotas de recuperación de los servicios médicos requeridos por la accionante, ordenados por el médico tratante de la misma, para el tratamiento del cáncer que padece. Cuarto.- Ordenar a la Dirección Seccional de Salud de Antioquia, prestar los servicios integrales a la afectada, tal como lo ha venido haciendo, sin poner como condición la cancelación de las cuotas de recuperación, los que deberá asumir la entidad en un $100 \%$ de acuerdo a los procedimientos, medicamentos, terapias y demás prescripciones de los médicos tratantes, en relación con la enfermedad que padece".

42 En el caso de la Sentencia T-510 de 2003, por ejemplo, se ordenó la provisión de alimentos y medicamentos hasta la prestación de servicios psicológicos. En la Sentencia T-725 de 2008, se ordenó la relación de un censo, la provisión de un albergue temporal y la entrega de ayuda humanitaria. 
Paralelamente, se encuentran las órdenes que disponen (i) la realización de estudios y evaluaciones previas $(28,57 \%)$ y (ii) el seguimiento y control sobre lo que se ha proferido (20\%). Este tipo particular de órdenes son esenciales en materia de política pública toda vez que permiten evidenciar, a través de un examen previo, las situaciones que han de ser objeto de tratamiento $y$, una vez diseñada y ejecutada determinada política o programa, permite objetivamente medir su impacto y hacer seguimiento y control de los niveles de eficacia y satisfacción que genera ${ }^{43}$. Este enfoque, por ejemplo, fue el que se dispuso en la sentencia T-772 de 2003 que ordenó

al Gerente del Fondo de Ventas Populares para que otorgue a los representantes de los vendedores informales la oportunidad de participar activamente en los procesos de evaluación y seguimiento de las políticas de recuperación del espacio público que diseña y adelanta el establecimiento público que él dirige, así como en la formulación de cualquier cambio o modificación a las mismas, con miras a garantizar efectivamente que tales políticas, así como los programas y medidas a través de los cuales se ejecuten, den pleno cumplimiento a las pautas constitucionales señaladas en el acápite 3.3. de esta providencia, a saber, (i) estar precedidas de un análisis cuidadoso de la evolución de la situación social y económica real de los destinatarios de tales políticas, programas o medidas, (ii) asegurar que las alternativas económicas ofrecidas a los vendedores informales correspondan en su alcance y cubrimiento a las dimensiones cambiantes de la realidad social y económica respecto de la cual habrán de aplicarse las políticas, programas y medidas en cuestión, y (iii) garantizar que dichas alternativas económicas sean ofrecidas a sus destinatarios con anterioridad al adelantamiento de las medidas de desalojo y decomiso tendientes a recuperar el espacio público, dando prioridad a los vendedores informales estacionarios y semiestacionarios.

Aunque este tipo de órdenes puede presentarse de manera paralela como acaba de exponerse, o de forma aislada -sentencias T-510 de 2003 o T-725 de 2008-44 donde sólo hay órdenes de seguimiento y control, el ideal jurídico es que ambas medidas coincidan, con miras a garantizar los principios de focalización, exactitud y eficacia con el complemento de la participación activa de la población.

\footnotetext{
43 Son múltiples los casos en que las órdenes de evaluación y seguimiento se presentan de forma paralela en una misma providencia, por ejemplo, en el caso de la sentencia T-608 de 2007se combinan ambos tipos de órdenes o la sentencia T-703 de 2012.

44 Que dispone lo siguiente: "Ordenar a la Secretaría General de la Corte Constitucional el envío de una copia de la presente decisión al Procurador General de la Nación y al Defensor del Pueblo para que, conforme a sus competencias, hagan seguimiento al cumplimiento de esta decisión”.
} 
Otro tipo de órdenes relevantes comprende aquellas referidas a la efectivización de los derechos -con reconocimiento expreso-, que para el caso de análisis representó un $22 \%$ de incidencia. Tratándose de políticas públicas, partir del reconocimiento de la efectivización de los derechos implica que, el eje sobre el cual se diseñan y ejecutan, corresponde al enfoque de derechos humanos que, para el objeto del presente estudio, se edificaría sobre los derechos tutelados en sede de revisión.

En conexión con lo anterior, otro tipo de orden corresponde a la restitución con una incidencia del 14,28\%, lo cual podría llegar a ser parte de una política pública. No obstante, este tipo de medidas se adecua más a las decisiones que tradicionalmente se adoptan en sede de tutela, toda vez que la finalidad de volver las situaciones fácticas o jurídicas al statu quo hace parte de la reparación in integrum que debe procurar el juez cuando conoce de este tipo de situaciones. En todo caso, para el presente estudio es importante mencionar que la mayoría de las órdenes que comprenden algún tipo de restitución, se refería a aquellos casos que involucraban la categoría de trabajo informal, donde la reubicación como orden adoptada por excelencia, permite al trabajador informal -en situación de pobreza- continuar con la actividad que venía desarrollando para ganar su sustento diario sin que se afecten sus derechos al trabajo y al mínimo vital. ${ }^{45}$

En el siguiente nivel de incidencia, se encuentran aquellas órdenes que disponen la adopción de políticas públicas en materia de pobreza $(11,42 \%)$, donde la tendencia que ha seguido la Corte Constitucional de Colombia consiste, de un lado, en (i) la formulación de las bases generales que habrán de fundamentar las políticas que se pretende adoptar y (ii) en exhortar a las autoridades administrativas competentes para la gestión y adopción de las políticas en aquellos casos donde son insuficientes o inexistentes ${ }^{46}$. En estas situaciones, las órdenes jurisprudenciales llevan inmersos varios factores esenciales: evaluación previa, diseño, gestión, ordenación del gasto público social, participación activa de la población, pro actividad, eficiencia, eficacia, seguimiento y control, entre otras.

Este rasgo que ha asumido el tribunal constitucional no es de poca monta, porque aquí es donde la jurisprudencia se presenta como instrumento legitimador para ampliar su competencia jurisdiccional a la dirección de políticas públicas,

45 Un claro ejemplo de esto último se encuentra en la sentencia T-729 de 2006, donde la Corte Constitucional ordenó restituir y reubicar a los vendedores ambulantes de la ciudad de Ibagué en un término de 10 días para que pudieran retomar las actividades que venían desarrollando, o ejercer algunas de carácter similar.

46 Ejemplo de esta situación son las sentencias T-510 de 2003, T-608 de 2007 y T-386 de 2013. 
aunque sea de manera indirecta. Lo anterior, en el entendido de que la Corte Constitucional fija a través de su jurisprudencia, los principios o parámetros básicos sobre los que se debe erigir la política, los sujetos beneficiarios, las autoridades que deben ejecutar e implementar, e incluso llega a ordenar la disposición de los recursos públicos que habrán de invertirse para el caso concreto.

En este punto, es donde la Corte Constitucional despliega su rol como juez que judicializa la política, toda vez que, a partir de un caso concreto, ordena la adopción de políticas públicas para garantizar el mismo nivel de protección para aquellas personas que se encuentran en la misma situación del accionante y, además, asegura la permanencia en el tiempo de medidas para evitar que continúe la conculcación de derechos fundamentales con ocasión del fenómeno multipolar de la pobreza.

Por supuesto, los límites competenciales del tribunal impiden que de manera directa pueda adoptar las políticas públicas, pues les corresponde a las autoridades gubernamentales elaborar, adoptar y ejecutar los programas que le ordena el tribunal constitucional. No obstante, podría llegar a afirmarse que, sin la intervención del juez constitucional, no se tendría la seguridad de que la administración actuaría o asumiría el mismo nivel de protección que ha sido ordenado judicialmente.

El hecho es que mediante providencias judiciales de seguimiento, el tribunal constitucional se cerciora de que sus órdenes se están ejecutando, de manera que interviene indirectamente en todo el proceso que conlleva la adopción, elaboración, puesta en marcha, ejecución y evaluación de la política pública, con el objetivo de modificar o aclarar el alcance de sus órdenes.

Por otro lado, se encuentran las órdenes de abstención $(5,71 \%$ de incidencia), donde la Corte profiere decisiones que implican la no continuación de un comportamiento determinado que genera un detrimento o conculcación a los derechos fundamentales de las personas que se encuentran en situación de pobreza y desposeimiento. Generalmente, este tipo de proveído se dirige a autoridades administrativas que en ejercicio de sus competencias ponen en riesgo la integridad de los derechos fundamentales o impiden su ejercicio cabal ${ }^{47}$.

\footnotetext{
47 Ejemplos de este tipo de orden se encuentran en la Sentencia T-772 de 2003, donde se establece en materia de trabajo informal que las autoridades de policía no podrán adoptar ninguna medida de desalojo o decomiso y deben abstenerse de aplicar la retención transitoria de los comerciantes informales, so pena de vulnerar el derecho al trabajo, al debido proceso y al mínimo vital. También la sentencia T-413 de 2013 es importante, porque en ella se ordena a la autoridad pública "no seguir obstaculizando" las posibilidades de la accionante de ser incluida en un programa de asistencia social en salud.
} 
Más abajo en nuestra escala, se encuentran los casos en los cuales se configura un deber de información en cabeza de las autoridades(5,71\%), referido a la publicación y difusión de datos de interés para la población en situación de pobreza, con el objeto de facilitar el acceso a canales de participación o mecanismos de reivindicación de sus derechos; así como otro tipo de órdenes adoptadas en el $17,14 \%$ de los casos que abarcan medidas de tipo pedagógico o divulgativo, que buscan abarcar la complejidad del fenómeno de la pobreza para conjurarla en un caso concreto.

Finalmente, se encuentran aquellos casos donde la Corte Constitucional no toma órdenes adicionales $(14,28 \%$ de incidencia) y se limita a confirmar y revocar las providencias sometidas a revisión.

\section{Resultados analíticos de la inVestigación: ¿CÓmo la dinámica de}

JUDICIALIZACIÓN DE LA POLÍTICA POR PARTE DE LA CORTE CONSTITUCIONAL

\section{COLOMBIANA HA CONTRIBUIDO A COMBATIR EFECTIVAMENTE EL}

\section{FENÓMENO DE LA POBREZA?}

En materia de judicialización de la política, habiendo visto las categorías de análisis identificadas para la realización del presente estudio se deben hacer las siguientes precisiones críticas:

- El papel de la Corte Constitucional de Colombia ha permitido reivindicar los derechos fundamentales de las personas que se encuentran en situación de pobreza extrema y desposeimiento y que han accedido a la protección judicial por parte de esta instancia judicial.

- Las órdenes proferidas por el tribunal constitucional, son adecuadas y eficaces, pero en la resolución de casos concretos, ya que, finalmente, ese es el objetivo primordial en sede de revisión. Por lo tanto, resulta arriesgado afirmar que la Corte Constitucional de Colombia es un auténtico gestor directo de políticas públicas en materia de pobreza, porque, como se dijo, la naturaleza de su función -en sede de revisión- es verificar la amenaza o vulneración de derechos fundamentales en un caso específico para proveer a través de su jurisprudencia de las soluciones a las que haya lugar. Ello no implica que el tribunal constitucional -de manera indirecta- no haya planteado una verdadera judicialización de la política en temas concretos que afectan a grupos de especial protección constitucional.

- La especificidad de la función de revisión de tutela determina que los efectos de las sentencias proferidas sea inter partes, lo cual, finalmente dificulta la elaboración de una política pública, porque de un lado (i) no tiene la virtualidad de 
generar efectos generales y, si así lo fuera, (ii) se desconocerían los efectos que el ordenamiento jurídico colombiano reconoce a las sentencias de tutela, que no alcanzan a generar efectos inter communis, ni erga omnes.

- Equiparar las decisiones de la Corte Constitucional de Colombia con verdaderas políticas públicas en materia de pobreza puede generar un cuestionamiento a una de las características esenciales de estas últimas: su cubrimiento general. Ello en razón a que, si bien el tribunal constitucional propende la salvaguarda de los derechos fundamentales, sólo puede hacerlo en aquellos casos que llegan a su conocimiento, en virtud de la interposición de las solicitudes de revisión de tutela, por ello, aunque puedan encontrase elementos importantes de focalización, lo cierto es que esta situación puede generar mayor discriminación o desigualdad en los casos que no son de su competencia y que no puede aprehender de oficio.

- La jurisprudencia de la Corte Constitucional de Colombia no tiene la virtualidad de combatir la multipolaridad del fenómeno ni la totalidad de las trampas de la pobreza, pero en todo caso, sienta reglas importantes que deben observarse para la promoción y protección de los derechos humanos por parte de las entidades estatales encargadas de elaborar y ejecutar la política pública en materia de pobreza.

- La dinámica de judicialización de la política desplegada por la Corte Constitucional de Colombia no comprende la toma de decisiones suficientemente homogéneas y amplias en materia de pobreza. No obstante, sienta bases y reglas, cuya observancia obligatoria dependerá del tipo de sentencia proferida y, en todo caso, sus pronunciamientos y decisiones constituyen una alerta importante en relación con las fallas de la autoridad administrativa encargada de diseñar, implementar y controlar las políticas públicas y los programas sociales en materia de pobreza.

- Ciertas categorías de órdenes establecidas en la jurisprudencia constitucional como la ordenación de gasto público social o la elaboración de políticas públicas pueden llegar a superar la misión que constitucionalmente se ha asignado al tribunal constitucional, excediendo el marco de su competencia aun dentro de una dinámica de judicialización de la política.

\section{A MODO DE CONCLUSIÓN}

Pobreza y derecho constitucional son dos elementos que conforman una relación de interdependencia mediante la interpretación que realiza el tribunal constitucional acerca del contenido, alcance y garantía de cada uno, de manera que no sólo permite la transformación de los conceptos jurídicos, sino también 
cuestionar y adaptar la institucionalidad estatal, la realidad social, el contexto económico y la democracia a las necesidades y requerimientos de la sociedad.

La lucha contra la pobreza requiere de la actuación mancomunada de los tres poderes públicos, pero sin que implique que uno pueda invadir la órbita de actuación del otro, porque se corre el riesgo de perder desde sus inicios el carácter participativo y el enfoque de derechos humanos que debe dar fundamento a la política pública. En ese sentido, se considera desde el presente trabajo que en materia de políticas públicas para la lucha contra la pobreza "la regulación por parte del tribunal constitucional consistiría en poner límites claros a los poderes legislativo y ejecutivo, ya sea declarando inexequibles las leyes y decretos o controlando que el poder ejecutivo desarrolle correctamente su labor, en este caso, atendiendo las demandas de los ciudadanos que recurren a la administración de justicia para satisfacer las necesidades de políticas públicas, como tradicionalmente lo ha hecho". ${ }^{48}$

Por consiguiente, la jurisprudencia constitucional desde las distintas categorías de análisis identificadas permite generar importantes reglas y estándares sobre igualdad y dignidad que se constituyen como parámetro para definir y evaluar las políticas públicas ${ }^{49}$ en materia de pobreza. Es allí donde la judicialización de la política encuentra su más adecuada expresión dentro de un sistema democrático con equilibrio de poderes y colaboración armónica.

Esta consideración nos permite afirmar que la interpretación prohijada por la Corte Constitucional de Colombia es adaptativa al contexto social y económico y que, en ese sentido, fija un contenido altamente garantista a su jurisprudencia ${ }^{50} \mathrm{a}$ través de dinámicas de judicialización de la política. Sin embargo, a pesar de esta amplia progresión todavía quedan muchos derechos por reivindicar, cambios institucionales importantes por implementar y garantías por materializar. Por esta razón compartimos la afirmación de Carvajal (2013) que ha señalado que:

"Parte del trabajo que aún nos queda es dotar a la Constitución y al derecho de contenidos sociales, $y$ fortalecer permanentemente las titularidades que posibiliten la superación de las desigualdades sociales y económicas para llegar a una sociedad justa. La Constitución y el orden legal en Colombia han sido utilizados como instrumento para los intereses de los sectores dominantes de la sociedad; sin embargo,

48 Castaño (2013), p. 137.

49 Abramovich y Pautassi (2006), p. 29.

50 Cifuentes (1995), p. 76. 
éste también puede ser instrumento de emancipación colectiva, el orden y la paz no se logran a través de modelos de represión, sino por medio de la realización efectiva de los derechos". 51

En todo caso, el papel de la jurisprudencia constitucional garantista en materia de pobreza resulta esencial para reivindicar una teoría de la democracia social que vaya más allá del Estado Social de Derecho, en la medida en que siente las bases para ir avanzando en los aportes positivos de la justicia y la participación social, la democratización de la sociedad y la exigibilidad de los derechos junto con su efectiva realización ${ }^{52}$. Este ejercicio en sede judicial permitirá que se sienten reglas importantes con el alcance propio de un precedente judicial que permitan resarcir la situación de vulnerabilidad y exclusión social de quienes se han visto sometidos a engrosar la esfera del desposeimiento socio económico.

A pesar de lo anterior, esta investigación ha encontrado que la jurisprudencia de la Corte Constitucional de Colombia no tiene la virtualidad de combatir la multipolaridad del fenómeno de la pobreza. Precisamente, la crítica más aguda que se desprende de los criterios que han sido identificados, pone en evidencia que el tribunal constitucional no actúa como un auténtico gestor de políticas públicas, lo que ocasiona serios problemas de desigualdad con las órdenes que profiere y lo pone ad portas de un sistema de populismo jurídico, perjudicial para el equilibrio de poderes.

Precisamente, los datos recolectados muestran que la Corte Constitucional, como tribunal de revisión de sentencias de tutela, ha fijado una serie de parámetros que protegen sólo a aquellas personas que logran acceder a este control; no obstante, la protección que irradia en sus sentencias, no alcanza a afectar a la mayor parte de la población que también se circunscribe en un ámbito de pobreza.

Por consiguiente, consideramos que la judicialización de la política en cabeza del tribunal constitucional, no debe perder de vista a aquellas personas condenadas por el Estado a vivir en situación de pobreza y que no tienen la posibilidad de acceder al control constitucional. Precisamente, esta investigación ha encontrado que los criterios de determinación y focalización por vía judicial han venido decantándose y que, podría ser útil, que la Corte Constitucional de Colombia empleara sus facultades para emitir órdenes que vayan más allá de la situación particular y atiendan a las verdaderas necesidades de la población.

51 Carvajal (2002), p. 189.

52 Arango (2010), p. 23. 
A pesar de lo anterior, entendemos claramente que el papel de la Corte Constitucional se ha venido circunscribiendo en el deber de las autoridades públicas de " $(\ldots$ ) corregir las visibles desigualdades sociales, a facilitar la inclusión y participación de sectores débiles, marginados y vulnerables de la población en la vida económica y social de la nación, y a estimular un mejoramiento progresivo de las condiciones materiales de existencia de los sectores más deprimidos de la sociedad". 53 .

\section{BiBLIOGRAFÍA CITADA}

Abramovich, Víctor y Pautassi, Laura Cecilia (2006): Dilemas actuales en la resolución de la pobreza. El aporte del enfoque de derechos. Ponencia presentada en las Jornadas Justicia y Derechos Humanos: políticas públicas para la construcción de ciudadanía, en el marco del Seminario Taller: Los Derechos Humanos y las políticas públicas para enfrentar la pobreza y la desigualdad (Buenos Aires, Unesco).

Aguirre Hernández, Jorge Manuel (2009): La pobreza desde lo jurídico. Una reflexión sobre el ordenamiento constitucional mexicano (México, Lex Artis), Cuadernos de Derecho, No 8.

Arango Rivadeneira, Rodolfo (2010): "Democracia Social, Jueces y Lucha contra la pobreza”, en Revista Nuevo Foro Penal (Vol. 6, No 74), pp. 11-28.

BENDOR, Ariel L. (2011-2012): "The Relevance of the Judicial Activism vs. Judicial Restraint Discourse", en Tulsa Law Review (Vol. 47, No 2), pp. 331-337.

Bотна, Henk (2011): "Representing the Poor: Law, Poverty and Democracy" en Stellenbosch Law Review (Vol. 22, No 3), pp. 501-520.

CarvajaL, Jorge (2002): "La justicia, el derecho y el conflicto social en Colombia", en El Otro Derecho (No 28), pp. 171-191.

Castaño Peña, Jairo Andrés (2013): "Análisis económico del activismo judicial: el caso de la Corte Constitucional Colombiana”, en Revista Derecho del Estado (No 31), pp. 119-160.

Cifuentes Muñoz, Eduardo (1995): "El Constitucionalismo de la Pobreza", en Dereito: Revista Xurídica da Universidade de Santiago de Compostela (Vol. IV, No 2), pp. 53-77.

53 Corte Constitucional de Colombia. Sentencia T-025 de 2004, M. P. Manuel José Cepeda. 
De Queiroz Barboza, Estefania María; Kozicki, Katya (2015): "Judicialization of Politics and the Judicial Review of Public Policies", en Revista Direito GV. Sao Paulo (Vol. 8, No 1), pp. 59-86.

De SA, Mariana Oliveira y Bonfim, Vinicius Silva (2015): “The Procedure of the Supreme Court Front the Phenomena of Judicialization of Politics and of Judicial Activism", en Brazilian Journal of Public Policy (Vol. 5, No 2), pp. 170-190.

Feoli Villalobos, Marco (2015): "El nuevo protagonismo de los jueces: una propuesta para el análisis del activismo judicial", en Revista de derecho (Coquimbo) (Vol. 22 No 2), pp. 173-198.

Ferejohn, John (2002): "Judicializing Politics, Politicizing Law", en Law and Contemporary Problems (Vol. 65, No 3), pp. 41-68.

FigueroA G.-H., Rodolfo (2009): "Justiciabilidad de los derechos económicos, sociales y culturales: discusión teórica”, en Revista chilena de derecho (Vol. 36, No 3), pp. 587-620.

Fraser, Nancy (2011): "Social Exclusion, Global Poverty, and Scales of (In) Justice: Rethinking Law and Poverty in a Globalizing World” en Stellenbosch Law Review (Vol. 22, No 3), pp. 452-462.

Henao Pérez, Juan Carlos (2013): "El juez constitucional: un actor de las políticas públicas", en Revista de Economía Institucional (Vol. 15, No 29), pp. 67-102.

LAHERA, Eugenio (2004): Politica y políticas públicas (Santiago de Chile, Naciones Unidas - CEPAL), Serie Políticas Sociales, No 95.

LePIANKA, Dorota (2003): "What Is Social Exclusion - A Brief Introduction to the Concept" en Polish Foreign Affairs Digest (Vol. 3, No 1), pp. 85-109.

Lo Vuolo, Rubén; Barbeito, Alberto; Pautassi, Laura y Rodríguez, Corina (2004). La pobreza... de la política contra la pobreza (Buenos Aires - Argentina, Centro Interdisciplinario para el Estudio de Políticas Públicas).

Marín, Aurelia-Camelia (2013): "Public Policies Explained", en Research and Science Today (Vol. 5, Supplement), pp. 203-211.

Perry, Michael J. (1984): "Judicial Activism”, en Harvard Journal of Law and Public Policy (Vol. 7, No 1), pp. 69-75.

Santiago, Alfonso (2008): "Sistema jurídico, teoría del derecho y rol de los jueces: las novedades del Neoconstitucionalismo", en Dikaion (No 17), pp. 131-155. 
SiERRA, Grenfieth (2009): "El juez constitucional: un actor regulador de las políticas públicas: El caso de la descentralización en Colombia”, (Bogotá D.C - Colombia, Editorial Universidad del Rosario).

STARK, Barbara (2009): “Theories of Poverty/the Poverty of Theory", en Brigham Young University Law Review (№ 2), pp. 381-430.

Uprimny YePES, Rodrigo (2007): "La judicialización de la política en Colombia: casos, potencialidades y riesgos", en Sur - Revista Internacional de Derechos Humanos (Vol. 4, Num. 6), pp. 52-69.

Velásquez Gavilanes, Raúl (2009): "Hacia una nueva definición del concepto "política pública”", en Desafios (Vol. 20), pp. 149-187.

\section{DOCUMENTOS CITADOS}

Ley No 1.437 de 18 de enero de 2011, Por la cual se expide el Código de Procedimiento Administrativo y de lo Contencioso Administrativo. Diario Oficial No 47.956 de 18 de enero de 2011.

Naciones Unidas, Consejo Económico y Social, Declaración de compromiso del Comité Administrativo de Coordinación en pro de la erradicación la pobreza, U.N. Doc. E/1998/73, de 22 de junio de 1998.

Naciones Unidas, Asamblea General, Resolución No 55/2 Declaración del Milenio, U.N. Doc. A/RES/55/2, de 13 de septiembre de 2000. 
Programa de las Naciones Unidas para el Desarrollo (PNUD) (2010): Breve Introducción a las Políticas Públicas para la Gobernabilidad Local en América Latina (curso de "Gobernabilidad Democrática Local y Procesos de Descentralización para el Desarrollo Humano", Escuela Virtual del PNUD)

ANEXo 1 - TABLA DE ANÁLISIS JURISPRUdENCIAL DE LA INVESTIGACIÓN

\begin{tabular}{|c|c|c|c|c|c|c|c|}
\hline Sentencia & Año & $\begin{array}{l}\text { Número de } \\
\text { sentencia }\end{array}$ & Tema & Norma & $\begin{array}{l}\text { Derecho cuya pro- } \\
\text { tección se invoca }\end{array}$ & Decisión & Órdenes \\
\hline Tutela & 1997 & T-495/97 & $\begin{array}{l}\text { Sujetos de especial } \\
\text { protección - Ter- } \\
\text { cera edad }\end{array}$ & N/A & $\begin{array}{l}\text { Derechos de la fami- } \\
\text { lia, a la vida, a unas } \\
\text { condiciones de vida } \\
\text { dignas, a la protec- } \\
\text { ción especial que } \\
\text { se debe a la tercera } \\
\text { edad y a la asistencia } \\
\text { pública. }\end{array}$ & $\begin{array}{ll}\text { Revoca } & y \\
\text { tutela } & \end{array}$ & $\begin{array}{l}\text { Económicas, Preven- } \\
\text { tivas, Publicidad, Co- } \\
\text { municación y Efecti- } \\
\text { vización de derechos }\end{array}$ \\
\hline Tutela & 1999 & T-307/99 & $\begin{array}{l}\text { Derecho de peti- } \\
\text { ción reforzado - } \\
\text { Sisben }\end{array}$ & N/A & $\begin{array}{l}\text { Habeas data, Igual- } \\
\text { dad, Participación y } \\
\text { Derecho de petición }\end{array}$ & $\begin{array}{l}\text { Revoca y } \\
\text { tutela }\end{array}$ & $\begin{array}{l}\text { Efectivización de } \\
\text { derechos, Reforma } \\
\text { administrativa y Pe- } \\
\text { dagógicas }\end{array}$ \\
\hline Tutela & 2002 & T-598/02 & $\begin{array}{l}\text { Deber de financia- } \\
\text { miento del estado } \\
\text { a pesar de situa- } \\
\text { ción de pobreza }\end{array}$ & N/A & Igualdad & Confirma & Ninguna \\
\hline Tutela & 2003 & T-190/03 & Salud - Sisben & N/A & Salud y Vida & $\begin{array}{l}\text { Revoca y } \\
\text { tutela }\end{array}$ & $\begin{array}{l}\text { Prestación de servi- } \\
\text { cios y Realización de } \\
\text { estudios }\end{array}$ \\
\hline Tutela & 2003 & T-719/03 & $\begin{array}{l}\text { Sujetos de especial } \\
\text { protección - mujer } \\
\text { cabeza de familia }\end{array}$ & N/A & $\begin{array}{l}\text { Seguridad personal } \\
\text { y Mínimo vital }\end{array}$ & $\begin{array}{ll}\text { Revoca } & y \\
\text { tutela } & \end{array}$ & $\begin{array}{l}\text { Procesales, Efectivi- } \\
\text { zación de derechos, } \\
\text { Realización de estu- } \\
\text { dios y Económicas }\end{array}$ \\
\hline Tutela & 2003 & T-772/03 & $\begin{array}{l}\text { Deberes del Esta- } \\
\text { do para erradicar } \\
\text { la Pobreza - caso } \\
\text { vendedores ambu- } \\
\text { lantes }\end{array}$ & $\mathrm{N} / \mathrm{A}$ & $\begin{array}{l}\text { Dignidad, Mínimo } \\
\text { vital y Debido pro- } \\
\text { ceso }\end{array}$ & $\begin{array}{l}\text { Revoca y } \\
\text { tutela }\end{array}$ & $\begin{array}{l}\text { Procesales, Econó- } \\
\text { micas, Inclusividad, } \\
\text { Adopción de nor- } \\
\text { mas, Efectividad de } \\
\text { los derechos, Medi- } \\
\text { das administrativas } \\
\text { y Medidas de abs- } \\
\text { tención }\end{array}$ \\
\hline Tutela & 2004 & T-397/04 & $\begin{array}{l}\text { Sujetos de especial } \\
\text { protección - per- } \\
\text { sona en condición } \\
\text { de discapacidad }\end{array}$ & N/A & $\begin{array}{l}\text { Derecho a tener una } \\
\text { familia y no ser se- } \\
\text { parado de ella }\end{array}$ & $\begin{array}{l}\text { Revoca y } \\
\text { tutela }\end{array}$ & Ninguna \\
\hline Tutela & 2003 & Т-510/03 & $\begin{array}{l}\text { Sujetos de especial } \\
\text { protección - niños }\end{array}$ & N/A & $\begin{array}{l}\text { Derecho a tener una } \\
\text { familia y no ser se- } \\
\text { parado de ella }\end{array}$ & $\begin{array}{l}\text { Revoca y } \\
\text { Tutela }\end{array}$ & $\begin{array}{l}\text { Restitución, Medi- } \\
\text { das administrativas, } \\
\text { Presupuestales, Pres- } \\
\text { tacionales, Econó- } \\
\text { micas, Seguimiento - } \\
\text { control, Información } \\
\text { - difusión y Política } \\
\text { pública }\end{array}$ \\
\hline
\end{tabular}




\begin{tabular}{|c|c|c|c|c|c|c|c|}
\hline Sentencia & Año & $\begin{array}{l}\text { Número de } \\
\text { sentencia }\end{array}$ & Tema & Norma & $\begin{array}{l}\text { Derecho cuya pro- } \\
\text { tección se invoca }\end{array}$ & Decisión & Órdenes \\
\hline Tutela & 2004 & T-607/04 & $\begin{array}{l}\text { Competencias de- } \\
\text { partamentales }\end{array}$ & N/A & $\begin{array}{l}\text { Salud, Seguridad so- } \\
\text { cial y Vida digna }\end{array}$ & $\begin{array}{l}\text { Revoca y } \\
\text { tutela }\end{array}$ & $\begin{array}{l}\text { Prestación de servi- } \\
\text { cios y Medidas ad- } \\
\text { ministrativas }\end{array}$ \\
\hline Tutela & 2006 & $\mathrm{~T}-523 / 06$ & $\begin{array}{l}\text { Sujetos de especial } \\
\text { protección - ter- } \\
\text { cera edad e indi- } \\
\text { gencia }\end{array}$ & N/A & $\begin{array}{l}\text { Vida digna e Igual- } \\
\text { dad }\end{array}$ & $\begin{array}{l}\text { Confirma y } \\
\text { niega }\end{array}$ & $\begin{array}{l}\text { Económicas, Medi- } \\
\text { das administrativas y } \\
\text { Vigilancia y control }\end{array}$ \\
\hline Tutela & 2006 & T-612/06 & $\begin{array}{l}\text { Sujetos de especial } \\
\text { protección - edu- } \\
\text { cación de menores }\end{array}$ & N/A & $\begin{array}{l}\text { Educación e Igual- } \\
\text { dad }\end{array}$ & $\begin{array}{l}\text { Revoca } \quad y \\
\text { tutela }\end{array}$ & $\begin{array}{l}\text { Medidas administra- } \\
\text { tivas, Efectivización } \\
\text { de derechos, Pedago- } \\
\text { gía y Estudios - eva- } \\
\text { luación }\end{array}$ \\
\hline Tutela & 2006 & T-729/06 & $\begin{array}{l}\text { Deberes del Esta- } \\
\text { do para erradicar } \\
\text { la pobreza }\end{array}$ & N/A & $\begin{array}{l}\text { Igualdad, Trabajo y } \\
\text { Mínimo vital }\end{array}$ & $\begin{array}{l}\text { Revoca y } \\
\text { tutela }\end{array}$ & $\begin{array}{l}\text { Medidas administra- } \\
\text { tivas y Restitución }\end{array}$ \\
\hline Tutela & 2007 & $\mathrm{~T}-114 / 07$ & $\begin{array}{l}\text { Acceso a la ad- } \\
\text { ministración de } \\
\text { justicia }\end{array}$ & N/A & $\begin{array}{l}\text { Acceso a la adminis- } \\
\text { tración de justicia }\end{array}$ & $\begin{array}{l}\text { Modificar } \\
\text { la sentencia }\end{array}$ & Ninguna \\
\hline Tutela & 2007 & T-608/07 & $\begin{array}{l}\text { Sujetos de especial } \\
\text { protección - per- } \\
\text { sona en condición } \\
\text { de discapacidad }\end{array}$ & N/A & $\begin{array}{l}\text { Igualdad y Digni- } \\
\text { dad }\end{array}$ & $\begin{array}{l}\text { Revoca y } \\
\text { tutela }\end{array}$ & $\begin{array}{l}\text { Estudio - evaluación, } \\
\text { Efectivización de } \\
\text { derechos, Medidas } \\
\text { administrativas, Pre- } \\
\text { supuestales, Formu- } \\
\text { lación de políticas } \\
\text { públicas y Segui- } \\
\text { miento y control }\end{array}$ \\
\hline Tutela & 2007 & $\mathrm{~T}-773 / 07$ & $\begin{array}{l}\text { Deberes del Esta- } \\
\text { do para erradicar } \\
\text { la pobreza }\end{array}$ & N/A & $\begin{array}{l}\text { Mínimo vital y Tra- } \\
\text { bajo }\end{array}$ & $\begin{array}{l}\text { Revoca } \quad y \\
\text { tutela }\end{array}$ & $\begin{array}{l}\text { Medidas administra- } \\
\text { tivas y Restitución }\end{array}$ \\
\hline Tutela & 2008 & T-566/08 & $\begin{array}{l}\text { Deberes del esta- } \\
\text { do para erradicar } \\
\text { la pobreza }\end{array}$ & N/A & $\begin{array}{l}\text { Vida digna, Míni- } \\
\text { mo vital, Trabajo y } \\
\text { Debido proceso }\end{array}$ & $\begin{array}{l}\text { Revoca y } \\
\text { tutela }\end{array}$ & No \\
\hline Tutela & 2008 & T-585/08 & $\begin{array}{l}\text { Vivienda - Sujetos } \\
\text { de especial protec- } \\
\text { ción - indigencia }\end{array}$ & N/A & Vivienda digna & $\begin{array}{l}\text { Revoca y } \\
\text { tutela }\end{array}$ & $\begin{array}{l}\text { Inclusión - partici- } \\
\text { pación }\end{array}$ \\
\hline Tutela & 2008 & T-630/08 & $\begin{array}{l}\text { Deberes del Esta- } \\
\text { do para erradicar } \\
\text { la pobreza - per- } \\
\text { sona en condición } \\
\text { de discapacidad }\end{array}$ & N/A & $\begin{array}{l}\text { Igualdad, Debido } \\
\text { proceso y Trabajo }\end{array}$ & $\begin{array}{l}\text { Revoca y } \\
\text { tutela }\end{array}$ & $\begin{array}{l}\text { Procesales, Restitu- } \\
\text { ción e Inclusión - } \\
\text { participación }\end{array}$ \\
\hline Tutela & 2008 & T-648/08 & Salud & N/A & $\begin{array}{l}\text { Salud, Vida y Dig- } \\
\text { nidad }\end{array}$ & $\begin{array}{l}\text { Revoca y } \\
\text { tutela }\end{array}$ & $\begin{array}{l}\text { Económicas y Pres- } \\
\text { tación de servicios }\end{array}$ \\
\hline Tutela & 2008 & T-651/08 & Mínimo vital & N/A & $\begin{array}{l}\text { Mínimo vital, Tra- } \\
\text { bajo y Vida }\end{array}$ & $\begin{array}{l}\text { Revoca } \quad y \\
\text { tutela }\end{array}$ & Económicas \\
\hline Tutela & 2008 & T-725/08 & Vivienda & $\mathrm{N} / \mathrm{A}$ & $\begin{array}{l}\text { Debido proceso, } \\
\text { Igualdad, Vida, Vi- } \\
\text { vienda en condicio- } \\
\text { nes de dignidad }\end{array}$ & $\begin{array}{l}\text { Revoca par- } \\
\text { cialmente y } \\
\text { tutela }\end{array}$ & $\begin{array}{l}\text { Estudios - evalua- } \\
\text { ción, Prestacionales, } \\
\text { Inclusión - partici- } \\
\text { pación, Información } \\
\text { - difusión y Segui- } \\
\text { miento y control }\end{array}$ \\
\hline
\end{tabular}




\begin{tabular}{|c|c|c|c|c|c|c|c|}
\hline Sentencia & Año & $\begin{array}{l}\text { Número de } \\
\text { sentencia }\end{array}$ & Tema & Norma & $\begin{array}{l}\text { Derecho cuya pro- } \\
\text { tección se invoca }\end{array}$ & Decisión & Órdenes \\
\hline Tutela & 2008 & T-1179/08 & $\begin{array}{l}\text { Deberes del esta- } \\
\text { do para erradicar } \\
\text { la pobreza }\end{array}$ & N/A & $\begin{array}{l}\text { Trabajo, Mínimo } \\
\text { vital, Salud y Digni- } \\
\text { dad Humana }\end{array}$ & $\begin{array}{l}\text { Revoca y } \\
\text { conced e } \\
\text { otra. }\end{array}$ & $\begin{array}{l}\text { Medidas administra- } \\
\text { tivas y Restitución }\end{array}$ \\
\hline Tutela & 2009 & $\mathrm{~T}-420 / 09$ & $\begin{array}{l}\text { Acceso a la ad- } \\
\text { ministración de } \\
\text { justicia }\end{array}$ & N/A & $\begin{array}{l}\text { Derechos del me- } \\
\text { nor, Mínimo vital } \\
\text { y móvil, Alimentos, } \\
\text { Debido proceso, } \\
\text { Vida, Integridad } \\
\text { personal, Educa- } \\
\text { ción, Calidad de } \\
\text { vida, Salud, Desa- } \\
\text { rrollo Integral y Re- } \\
\text { creación }\end{array}$ & Confirma & Ninguna \\
\hline Tutela & 2009 & T-921/09 & $\begin{array}{l}\text { Deberes del esta- } \\
\text { do para erradicar } \\
\text { la pobreza }\end{array}$ & N/A & $\begin{array}{l}\text { Trabajo y Vida dig- } \\
\text { na }\end{array}$ & $\begin{array}{l}\text { Revoca y } \\
\text { tutela }\end{array}$ & $\begin{array}{l}\text { Medidas adminis- } \\
\text { trativas, Efectividad } \\
\text { de los derechos, Es- } \\
\text { tudios - evaluación, } \\
\text { Diseño - implemen- } \\
\text { tación, Política pú- } \\
\text { blica, Prestaciones, } \\
\text { Participación - in- } \\
\text { clusión, Seguimiento } \\
\text { y control }\end{array}$ \\
\hline Tutela & 2011 & $\mathrm{~T}-716 / 11$ & Pensiones & N/A & $\begin{array}{lr}\text { Mínimo } & \text { vital, } \\
\text { Igualdad y } & \text { Debido } \\
\text { Proceso } & \end{array}$ & $\begin{array}{l}\text { Revoca y } \\
\text { tutela }\end{array}$ & $\begin{array}{l}\text { Económicas y Pro- } \\
\text { cesales }\end{array}$ \\
\hline Tutela & 2012 & $\mathrm{~T}-285 / 12$ & $\begin{array}{l}\text { Seguridad alimen- } \\
\text { taria - Sujetos de } \\
\text { especial protec- } \\
\text { ción - discapaci- } \\
\text { dad }\end{array}$ & N/A & Salud y Vida digna & Confirma & $\begin{array}{l}\text { Medidas administra- } \\
\text { tivas y Eficacia de los } \\
\text { derechos }\end{array}$ \\
\hline Tutela & 2012 & $\mathrm{~T}-516 / 12$ & Vivienda digna & N/A & $\begin{array}{l}\text { Vivienda digna y } \\
\text { Familia }\end{array}$ & Confirma & Ninguna \\
\hline Tutela & 2012 & T-696/12 & $\begin{array}{l}\text { Sujetos de especial } \\
\text { protección - Ter- } \\
\text { cera Edad }\end{array}$ & N/A & $\begin{array}{l}\text { Debido proceso, } \\
\text { Igualdad, Mínimo } \\
\text { Vital y Protección } \\
\text { especial personas de } \\
\text { la tercera edad }\end{array}$ & $\begin{array}{l}\text { Revoca y } \\
\text { tutela }\end{array}$ & $\begin{array}{l}\text { Estudios - evalua- } \\
\text { ción, Prestacionales } \\
\text { y Económicas }\end{array}$ \\
\hline Tutela & 2012 & $\mathrm{~T}-703 / 12$ & $\begin{array}{l}\text { Deberes del estado } \\
\text { para erradicar la } \\
\text { pobreza - Trabajo } \\
\text { informal }\end{array}$ & N/A & $\begin{array}{l}\text { Mínimo vital y Tra- } \\
\text { bajo }\end{array}$ & $\begin{array}{l}\text { Revoca y } \\
\text { tutela }\end{array}$ & $\begin{array}{l}\text { Estudios - evalua- } \\
\text { ción, Prestacionales, } \\
\text { Económicas e Inclu- } \\
\text { sión - participación }\end{array}$ \\
\hline Tutela & 2012 & T-929/12 & $\begin{array}{l}\text { Sujetos de especial } \\
\text { protección - terce- } \\
\text { ra edad }\end{array}$ & N/A & $\begin{array}{l}\text { Personalidad jurídi- } \\
\text { ca, Derecho de pe- } \\
\text { tición, Debido pro- } \\
\text { ceso y Mínimo vital }\end{array}$ & $\begin{array}{l}\text { Revoca } \quad y \\
\text { tutela }\end{array}$ & $\begin{array}{l}\text { Medidas adminis- } \\
\text { trativas Económicas } \\
\text { Prestacionales Parti- } \\
\text { cipación - inclusión }\end{array}$ \\
\hline Tutela & 2013 & T-207/13 & $\begin{array}{l}\text { Sujetos de especial } \\
\text { protección - terce- } \\
\text { ra edad }\end{array}$ & N/A & $\begin{array}{l}\text { Debido proceso, } \\
\text { Mínimo vital, Vida } \\
\text { digna e Igualdad }\end{array}$ & $\begin{array}{l}\text { Revoca y } \\
\text { tutela }\end{array}$ & $\begin{array}{l}\text { Medidas administra- } \\
\text { tivas, Económicas, } \\
\text { Seguimiento - con- } \\
\text { trol e Inclusión - } \\
\text { participación }\end{array}$ \\
\hline
\end{tabular}




\begin{tabular}{|c|c|c|c|c|c|c|c|}
\hline Sentencia & Año & $\begin{array}{l}\text { Número de } \\
\text { sentencia }\end{array}$ & Tema & Norma & $\begin{array}{l}\text { Derecho cuya pro- } \\
\text { tección se invoca }\end{array}$ & Decisión & Órdenes \\
\hline Tutela & 2013 & T-386/13 & $\begin{array}{l}\text { Deberes del estado } \\
\text { para erradicar la } \\
\text { pobreza - trabajo } \\
\text { informal - mujer }\end{array}$ & N/A & $\begin{array}{l}\text { Mínimo vital, Tra- } \\
\text { bajo, Debido pro- } \\
\text { ceso y Confianza } \\
\text { legítima }\end{array}$ & $\begin{array}{l}\text { Revoca } \quad y \\
\text { tutela }\end{array}$ & $\begin{array}{l}\text { Estudios, Restable- } \\
\text { cimiento, Inclusión } \\
\text { - participación, Pres- } \\
\text { tacionales y Diseño - } \\
\text { implementación }\end{array}$ \\
\hline Tutela & 2013 & T-413/13 & $\begin{array}{l}\text { Sujetos de especial } \\
\text { protección - terce- } \\
\text { ra edad }\end{array}$ & $\mathrm{N} / \mathrm{A}$ & $\begin{array}{l}\text { Dignidad humana, } \\
\text { Salud, Seguridad } \\
\text { social, Vida digna y } \\
\text { Mínimo vital }\end{array}$ & $\begin{array}{l}\text { Revoca y } \\
\text { tutela }\end{array}$ & $\begin{array}{l}\text { Inclusión - participa- } \\
\text { ción, Abstención y } \\
\text { Económicas }\end{array}$ \\
\hline Tutela & 2013 & T-631/13 & Vivienda & N/A & $\begin{array}{l}\text { Vivienda digna, } \\
\text { Dignidad humana, } \\
\text { Integridad familiar e } \\
\text { Igualdad }\end{array}$ & $\begin{array}{l}\text { Revoca } \quad y \\
\text { tutela }\end{array}$ & $\begin{array}{l}\text { Medidas administra- } \\
\text { tivas, Estudio - eva- } \\
\text { luación, Inclusión } \\
\text { - participación y Se- } \\
\text { guimiento - control }\end{array}$ \\
\hline Tutela & 2014 & $\mathrm{~T}-383 \mathrm{~A} / 14$ & $\begin{array}{l}\text { Sujetos de especial } \\
\text { protección - terce- } \\
\text { ra edad }\end{array}$ & N/A & $\begin{array}{l}\text { Mínimo vital y Vida } \\
\text { digna }\end{array}$ & $\begin{array}{l}\text { Revoca } \quad y \\
\text { tutela }\end{array}$ & $\begin{array}{l}\text { Medidas administra- } \\
\text { tivas, Inclusión - par- } \\
\text { ticipación y Efectivi- } \\
\text { dad de los derechos }\end{array}$ \\
\hline Tutela & 2015 & T-007/15 & $\begin{array}{l}\text { Sujetos de especial } \\
\text { protección - disca- } \\
\text { pacidad }\end{array}$ & N/A & $\begin{array}{l}\text { Dignidad humana, } \\
\text { Vida digna, Igual- } \\
\text { dad, Mínimo vital, } \\
\text { Debido proceso y } \\
\text { Seguridad social }\end{array}$ & $\begin{array}{l}\text { Revoca y } \\
\text { tutela }\end{array}$ & Económicas \\
\hline Tutela & 2015 & T-025/15 & $\begin{array}{l}\text { Sujetos de especial } \\
\text { protección - ter- } \\
\text { cera edad e indi- } \\
\text { gencia }\end{array}$ & N/A & $\begin{array}{l}\text { Mínimo vital y Vida } \\
\text { digna }\end{array}$ & $\begin{array}{l}\text { Revoca } \quad y \\
\text { tutela }\end{array}$ & $\begin{array}{l}\text { Seguimiento y con- } \\
\text { trol, Acompañamien- } \\
\text { to, Colaboración, } \\
\text { Económicas (recono- } \\
\text { cimiento subsidios) y } \\
\text { Reintegración }\end{array}$ \\
\hline
\end{tabular}

